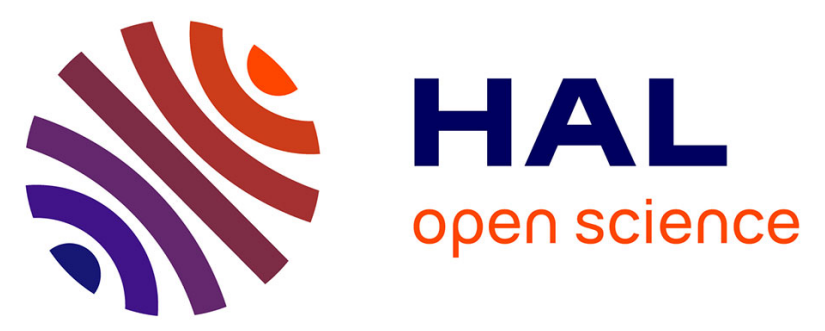

\title{
Preparation, Luminescent Properties and Bioimaging Application of Quantum Dots Based on $\mathrm{Si}$ and $\mathrm{SiC}$
}

\author{
V. Skryshevsky, T. Serdiuk, Yuriy Zakharko, S. Alekseev, Alain Geloen, \\ Vladimir Lysenko
}

\section{- To cite this version:}

V. Skryshevsky, T. Serdiuk, Yuriy Zakharko, S. Alekseev, Alain Geloen, et al.. Preparation, Luminescent Properties and Bioimaging Application of Quantum Dots Based on Si and SiC. Springer. Functional Nanomaterials and Devices for Electronics, Sensors and Energy Harvesting, 323-348, Alexei Nazarov; Francis Balestra; Valeriya Kilchytska; Denis Flandre, 2014, 10.1007/978-3-319-08804-4_15 . hal-01490305

\section{HAL Id: hal-01490305 \\ https://hal.science/hal-01490305}

Submitted on 30 Jun 2021

HAL is a multi-disciplinary open access archive for the deposit and dissemination of scientific research documents, whether they are published or not. The documents may come from teaching and research institutions in France or abroad, or from public or private research centers.
L'archive ouverte pluridisciplinaire HAL, est destinée au dépôt et à la diffusion de documents scientifiques de niveau recherche, publiés ou non, émanant des établissements d'enseignement et de recherche français ou étrangers, des laboratoires publics ou privés. 


\title{
Preparation, Luminescent Properties and Bioimaging Application of Quantum Dots Based on Si and SiC
}

\author{
Valeriy A. Skryshevsky, Tetiana Serdiuk, Yuriy E. Zakharko, \\ Sergei A. Alekseev, Alain Géloën and Vladimir Lysenko
}

\begin{abstract}
Well-known, the interest to the colloidal solution with quantum dots (QDs) lies in their fluorescence properties. Among the advantages of QDs are the high resistance to photooxidation, the size and composition variation allowing to obtain the narrow emission spectra with high quantum yield from the ultraviolet to the near infrared region. In this chapter we present the last achievements in forming and bio-medical applications of luminescent $\mathrm{Si}$ and $\mathrm{SiC}$ QDs. It is shown that a broad size distribution of Si QDs are obtained at electrochemical etching. The dimensions of the Si QDs undergone filtering in colloidal solution vary discretely with a radius quantum equal to $0.12 \mathrm{~nm}$. Existing of this quantum may correspond to step-like increasing of Si QDs radius on one new shell at the surface of Si QDs. The formed QDs show intense luminescent in visual region. However, one of the major drawbacks of Si QDs for bio-medical application is instability over time in water or buffer solutions. To overcome this drawback the several methods of surface functionalization are discussed. The SiC QDs are stable in water solutions and do not require supplementary surface functionalisation for bioimaging. A strong fluorescence from the SiC QDs, which undoubtedly penetrate into the cell, has been
\end{abstract}

\footnotetext{
V.A. Skryshevsky $(\square) \cdot$ T. Serdiuk

Institute of High Technologies, Taras Shevchenko National University of Kyiv, 64 Volodymyrska Str, Kyiv 01601, Ukraine

e-mail: skryshevsky@yandex.ru

T. Serdiuk · Y.E. Zakharko · V. Lysenko

Nanotechnology Institute of Lyon (INL), University of Lyon, UMR-5270, CNRS,

INSA de Lyon, 69621 Villeurbanne, France

S.A. Alekseev

Chemistry Faculty, Taras Shevchenko National University of Kyiv, 64 Volodymyrska Str, Kyiv 01601, Ukraine

T. Serdiuk · A. Géloën

CarMeN Laboratory, U 1060 INSERM, INSA de Lyon, 69621, Villeurbanne, France
} 
observed. The studying of health and cancer cells using SiC QDs shows that simple modification of surface charge of QDs gives strong opportunity to target the same QDs in intracellular space with their preferential localisation inside or outside the cell nucleus.

\section{Introduction}

Quantum dots (QDs) are semiconductor nanoparticles in which "quantum confinement" effect is observed [1]. Quantum confinement of electrons in semiconductor nanoparticles is observed when a crystallite radius less than the Bohr exciton radius (5 $\mathrm{nm}$ for silicon) and results in specific optical and electronic properties - size dependent bandgaps and thus a Stokes shift with high quantum yield photoluminescence.

Structurally, the central part of QDs consists of a core composed of a variety of substances such as $\mathrm{A}^{\mathrm{IV}}, \mathrm{A}^{2} \mathrm{~B}^{6}, \mathrm{~A}^{3} \mathrm{~B}^{5}$ and more complex semiconductors which can be amorphous or crystalline, doped and undoped [2]. The core can be covered by other semiconductor shell and stabilizing layer. Depending on functional application of QDs this layer can be hydrophilic or hydrophobic. The linkers and ligands can be attached to these layers allowing formation of different complex. The examples of possible materials for core, doping ions, shell, stabilizing layer, linkers and ligands are presented in Fig. 1.

Due to their specific photophysical, magnetic, electronic and biological properties quantum dots are widely applied in electronics and optoelectronics (light emission diodes, memory devices, displays), photochemistry (hydrogen generation, sensitizes, photoelectrodes), analytical chemistry (chemical analysis), molecular biology and medicine (biosensors, fluorescent labels, photodynamic therapy, drug biotracking), etc. [1-4].

In the last few decades, the emergence of nanotechnology gave rise to exciting developments in the field of cell biology. Indeed, the ability to control matter at the nanoscale length paves the way for the sensing of biological systems at the level of single molecules by optical or electrical detection. The implementation of QDs for use in cell labeling has been one of the fastest growing areas in this field. The reason for this intense research activity, in particular fluorescence labeling, lies in the considerable advantages of semiconductor QDs over the classically used organic dye molecules or fluorescent proteins. Numerous reviews have been devoted to these QDs [1-9] including the method of QDs formation and possible application to bioimaging. Here we review the last achievements in the branch of $\mathrm{Si}$ and $\mathrm{SiC}$ QDs formation by electrochemical etching, their surface functionalization, analysis of luminescent properties of QDs colloidal solutions, and different bio-medical application. 


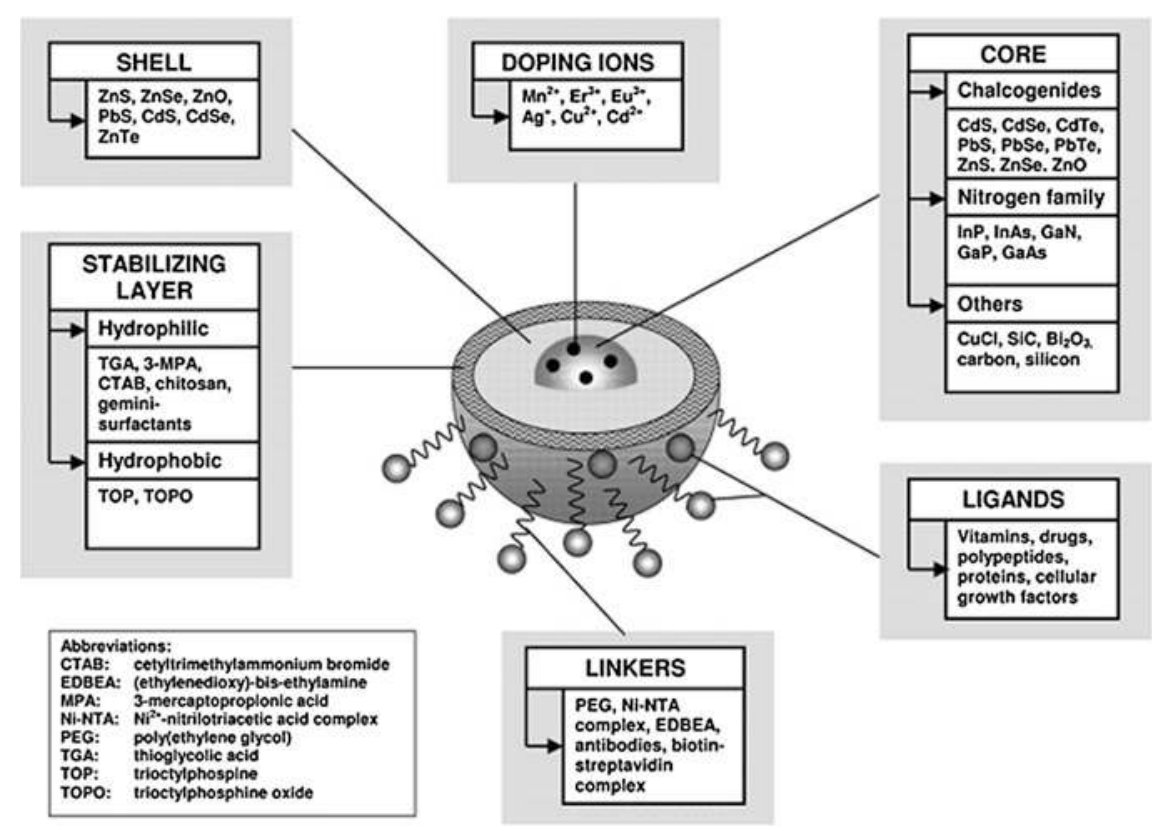

Fig. 1 Scheme of quantum dot structure (from [2])

\section{Properties and Advantages of Colloidal Solutions with QDs}

The interest in colloidal solution with QDs lies in their fluorescence properties. Among the advantages of QDs, the principal one is the higher resistance of QDs to light-induced reactions such as photooxidation. This photochemical inertness known as the photobleaching phenomenon prevents the degradation of luminescence properties with time. Another important feature of QDs is their size and composition-induced tunable emission spanning from the ultraviolet to the near infrared (UV to NIR) with a narrow emission spectra and high quantum yield. The conjugation of a narrow emission with a large effective Stokes shift [8, 10], a constant emission wavelength no matter what excitation wavelength is used [11], and a broad absorption spectrum are key parameters to achieve multiplexed imaging as the fluorescence signal of each QD can be readily separated and individually analyzed using a single excitation source. This multicolor imaging potentiality is particularly interesting for the monitoring of intracellular processes $[3,12]$. As the last advantage, it is also important to note that QDs have orders of magnitude larger cross sections for two-photon excitation compared to the organic chromophore. Thanks to this property, infrared excitation in the transparency window of tissues $(700-900 \mathrm{~nm})$ can be used with visible radiation to perform fluorescence detection. 

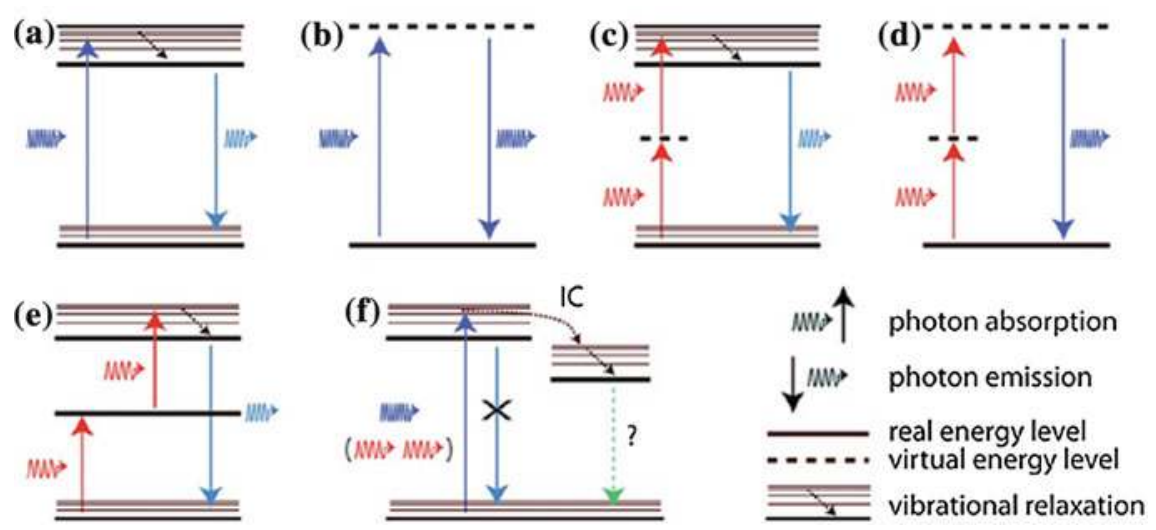

Fig. 2 a One-photon excited fluorescence. b Linear scattering. c Two-photon-excited fluorescence. d Second harmonic generation. e Sequential absorption and upconverted emission. f Principle of molecular bleaching showing intersystem crossing upon one- or two-photon absorption (from [7])

Besides fluorescence (one photon and two-photon excited) we can note other effects like linear scattering, second harmonic generation, sequential absorption and upconverted emission. The schemes in Fig. 2 summarize emission effects in QDs that can be applied to bio-medical applications (see detailed explanation in [7]).

QDs present also two important drawbacks. The first one is that most QDs, as synthesized, have hydrophobic organic ligands coating their surface [13]. To make the QDs water soluble, their organophilic surface species have to be exchanged with more polar species. A complex multilayer [14] ligand shell has then to be realized, which leads in some cases of nonspecific optical absorption. The second and the major drawback concerns cytotoxicity. For example, the widely used II-VI semiconductor QDs (e.g. CdSe) were found to be cytotoxic through the release of free cadmium ions $[15,16]$. As the result, these QDs strongly influence biological cell function and their application in efficient cell imaging is limited. Therefore, a protective shell ( $\mathrm{ZnS}$ or a polymer, for example) must be systematically added to prevent cell death when using these types of QDs. To completely avoid this problem, one has to use QDs on the basis of more benign materials such as group IV semiconductors, first of all $\mathrm{Si}$ and $\mathrm{SiC}$ QDs.

\section{Technology of Colloidal Solution of Si QDs}

Different approaches have been proposed and described in literature to create $\mathrm{Si}$ nanoparticles and $\mathrm{QD}_{\mathrm{S}}$. The isolated particles were obtained from a gas-phase preparation using silanes or other Si sources via thermal decomposition, thermal annealing, reactive sputtering, thermal vaporization, microwave plasma, gasevaporation, chemical vapour deposition $[1,9,17-20]$. 
"Wet chemistry" route to Si QDs typically involves the reaction of Zintl salts (KSi/NaSi) or reductive organometallic Si compounds with $\mathrm{SiCl}_{4}$ or $\mathrm{NH}_{4} \mathrm{Br}$ [21, 22]. Chemical reduction of silicon halogenides $\left(\mathrm{SiX}_{4} ; \mathrm{X}=\mathrm{Cl}\right.$ or $\left.\mathrm{Br}\right)$ by $\mathrm{LiAlH}_{4}$ in water-free reverse-micelle solutions gives Si QDs with narrow size distribution [23]. However, comparing to chemical route, electrochemical anodization is much more reproducible and simple technique for the fabrication of Si QDs emitting light in a large spectral range at room temperature under photoexcitation. Visible light emitting colloidal Si QDs are extensively studied [1]. Otherwise UV emitting Si QDs were only mentioned in a few papers [24-26], because it is relatively difficult to control fabrication of stable and homogeneously distributed Si QDs with dimensions less than $1.5 \mathrm{~nm}$ having the energy band gaps larger than $3 \mathrm{eV}$.

Commonly the anodization to prepare $\mathrm{Si}$ QDs as well as porous silicon (PS) takes place in the mixtures of $\mathrm{HF}$ (able to transform silicon into soluble $\mathrm{H}_{2} \mathrm{SiF}_{6}$ under anodization) and organic solvent (commonly ethanol) decreasing the wetting angle and thus allowing the penetration of electrolyte inside pores of PS. An experimental protocol for the preparation of $\mathrm{Si}$ QDs with desired emission wavelength (from NIR to UV) was described in details in the works [26, 27]. At the first stage, highly porous $(>90 \%) 300 \mu \mathrm{m}$ thick PS layer was prepared by anodization (current density $j=55 \mathrm{~mA} / \mathrm{cm}^{2}$ ) of p-type $(1-10 \Omega \mathrm{cm}$ ) boron-doped (100)-oriented Si wafers with a backside Al ohmic contact in 1:1 (v:v) mixture of $48 \%$ aqueous $\mathrm{HF}$ and absolute ethanol during $2 \mathrm{~h}$. To remove all HF traces the layer was washed several times in absolute ethanol and naturally dried, which resulted in its self-transformation into a strongly hydrogenated PS micropowder with about $6.5 \%$ mass content of $\mathrm{H}$ [27]. Finally the micropowder was mechanically grinded and dispersed in absolute ethanol, giving Si QDs saturated colloidal solution with $5 \mathrm{mg} / \mathrm{ml}$ concentration.

Transmission Electron Microscopy (TEM) pictures shown in Fig. 3 give a general view of quasi-spherical Si particles constituting the nanopowder suspension into the initial colloidal solution. As one can see, the general size distribution of the shown particles is relatively large. In particular, the initial nanopowder consists of large $(>10 \mathrm{~nm}$ ) porous particles (Fig. $3 \mathrm{~b}$ ) and numerous small denser

(a)

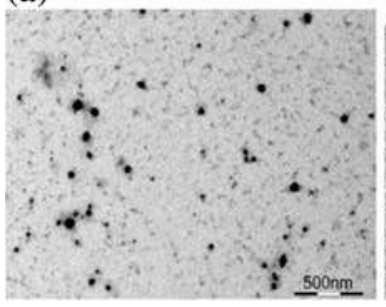

(b)

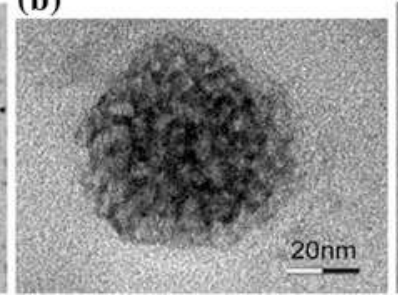

(c)

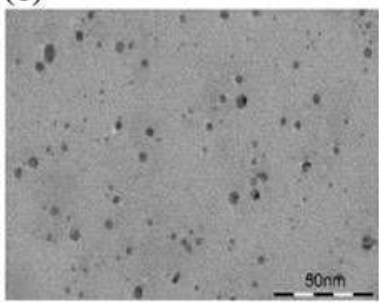

Fig. 3 TEM pictures of Si NPs constituting the initial strongly hydrogenated PS nanopowder: a general view; b large porous NPs; c small dense Si NPs with dimensions less than $5 \mathrm{~nm}$ (from [26]) 
Fig. 4 PL spectrum of the initial PS nanopowder in ethanol solution and its evolution upon sedimentation and moderate centrifugation (from [26])

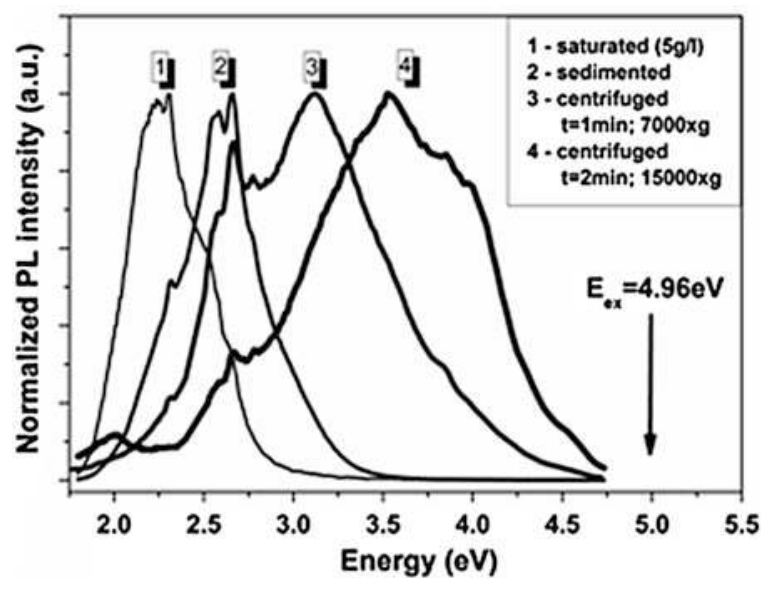

$(<10 \mathrm{~nm})$ particles (Fig. 3c). Total absence of clearly defined electron diffraction features indicates an amorphous-like state of the studied particles [27]. Clear and dark spots of the large porous particles (Fig. 3b) correspond to the pits and solid $\mathrm{Si}$ phase, respectively. In general, their shape was already described in terms of fractal geometry [28]. As for the small $(<10 \mathrm{~nm})$ particles (Fig. 3c), they are well known to exhibit highly efficient luminescence in a large spectral range due to quantum and spatial confinements of photogenerated charge carriers and these particles can be considered as SiQDs.

Figure 4 shows normalized photoluminescence (PL) spectra of the Si QDs in ethanol solutions [26]. First, the PL signal of the initial saturated solution is represented by spectrum 1. It is very similar to a usual PL spectrum of a red emitting PS layer. The spectra blueshifting in comparison to the initial PL is observed after sedimentation in the dark during 1 day (curve 2). Associating both PL spectra to particular size distributions of SiQDs and taking into account that the emission energy for the smaller QDs is higher, the observed sedimentationinduced evolution of the PL signal can be explained by the removal of the largest submicron PS QDs from the ethanol solution. Thus, the observed green-blue PL maxima of spectrum 2 may correspond to luminescence of the smaller porous QDs as those shown in Fig. 3b, for example. Further centrifugation leads to almost complete elimination of the QDs with dimensions larger than $2 \mathrm{~nm}$ from the colloidal solution. The PL spectrum 4 of this doubly centrifuged solution has a main maximum at $3.5 \mathrm{eV}$ and a set of other UV peaks at the high energy wing situated in the spectral region between 3.5 and $4.5 \mathrm{eV}$.

In $[29,30]$ we proposed a new method allowing more precise size selection of colloidal Si QDs. This approach is based on the use of meso-porous Si (meso-PS) free standing membranes as QDs filters (Fig. 5). In particular, due to auto-filtration phenomenon an efficient filtering was achieved and size quantization of the amorphous Si QDs was brought to the fore. Via variation of the porosity and thickness of meso-porous layer it is possible to obtain PL spectra with maxima 

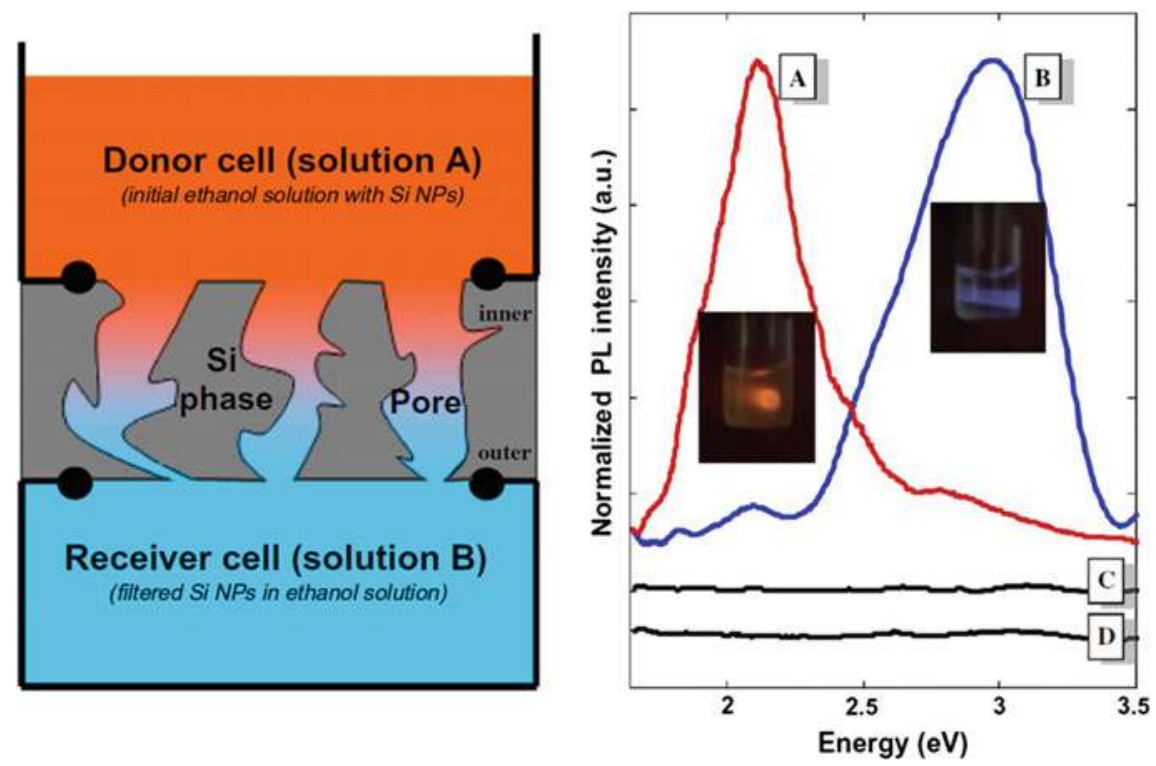

Fig. 5 Left Scheme of a double-tank homemade hermetic filtering set-up with upper (donor) cell and bottom (receiver) cell and Right PL spectra with corresponding photos of initial (curve A) and filtered (curve B) ethanol solutions with dispersed Si QDs. PL signals from pure absolute ethanol and from pure ethanol without Si QDs passed through the meso-PS membrane are represented by non-normalized spectra $C$ and $D$, respectively (from [29])
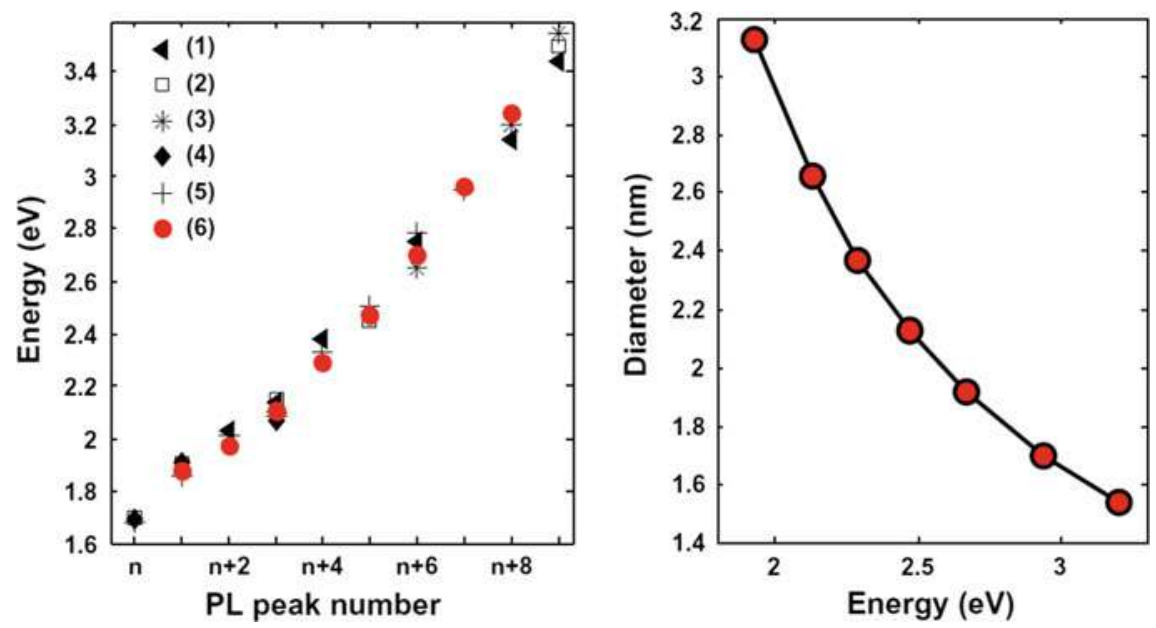

Fig. 6 Left spectral positions of PL maxima/shoulders reported in (1) [31], (2) [32], (3) [26], (4) [33], (5) [34], and (6) [29]; Right dependence of Si QDs size calculated according to the model described in [35] on the PL peak energies reported in [29] 

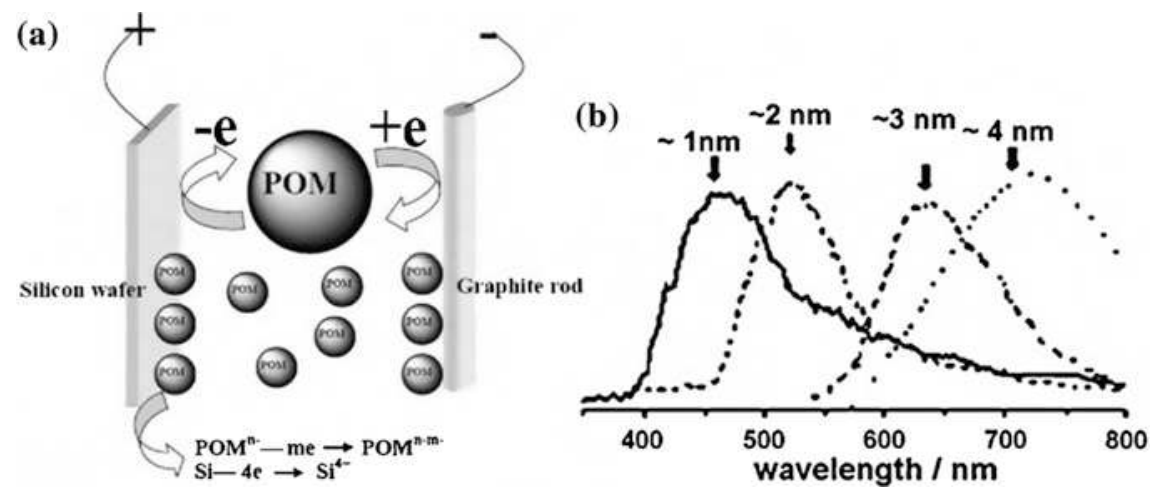

Fig. 7 Scheme for the POM-assisted electrochemical etching process (a). Typical PL spectra of $\mathrm{SiQDs}$ with sizes ranging from 1 to $4 \mathrm{~nm}$ (b) from [9]

from 1.7 to $3.4 \mathrm{eV}$. Energy positions of these features are summarized in Fig. 6. The lowest (in terms of energy) feature is designated as $n$ and all others as $n+i$, where $i$ is the index number. A remarkable coincidence of the data for each PL peak number can be stated. In particular, one can deduce from Fig. 6 that the PL energy values seem to vary discretely which is especially interesting taking into account total independence of the picked out data.

Since each spectral energy value assigned to a specific QD dimension, Fig. 6b shows this correlation according to the model of Delerue et al. [35] for which:

$$
\operatorname{Eg}(\mathrm{d})=1.167+3.73 * \mathrm{~d}^{-1.39}
$$

where $E_{g}(d)$ is the energy band gap of a spherical-like QD with diameter $d$. The QD diameter was estimated from Eq. (1) for each spectral PL feature $n+i$ characterized by its proper energy value $E_{g}(d)$. Thus, in frame of experimental errors, Fig. 6b shows that dimensions of the Si QDs undergone filtering vary discretely with a radius quantum equal to $0.12 \mathrm{~nm}$. Existing of this quantum may correspond to step-like increasing of Si QDs radius on one new shell at the surface of Si QDs.

The chromatography and other complex separation methods were applied to separate electrochemically etched Si QDs into monodisperse fractions [1, 9, 36-38].

For particle size control, Kang et al. have developed a polyoxometalate (POM)assisted electrochemical method, which yielded highly monodisperse Si dots (1, 2, 3, and $4 \mathrm{~nm}$ ) with a narrow size distribution requiring no further separation (Fig. 7) [36]. It represents a convenient and rational synthesis of a variety of Si nanostructures via the simple control of current density and choice of catalyst POMs. POMs clearly play a vital role incontrolling the size of Si dots and formation of Si nanostructures. The size control of Si dots may be attributed to the unique electronic characteristics of POMs in gaining and donating electrons simultaneously while keeping their structure unchanged. 


\section{Grafting of Si QDs and Their Application for Bioimaging}

One of the major drawbacks of SiQDs for application for bioimaging is their instability over time in water or buffer solutions. It is well-known that PS surface slowly oxidizes in air which is resulting in degradation of optical and luminescent properties. Several methods have been used to achieve a change in the surface composition for improving the stability of materials. The PS passivation can be achieved by replacing the $\mathrm{Si}-\mathrm{H}_{\mathrm{x}}$ bonds with stronger $\mathrm{S}-\mathrm{C}$ and $\mathrm{Si}-\mathrm{OC}$ bonds [39, 40]. Fortunately, the hydride species which cover the PS surface after Si etching provide a versatile starting point for various reactions, allowing the attachment of different species. An application of carbon grafting is prospective due to the fact that carbon directly bonded to silicon stabilizes porous Si against dissolution in aqueous solutions [41].

$\mathrm{Si}-\mathrm{C}$ bonds are usually formed on hydride-terminated porous $\mathrm{Si}$ surfaces by hydrosilylation, i.e. an addition of $\mathrm{Si}-\mathrm{H}$ fragments to unsaturated bonds of alkene or alkyne according to Scheme 1 [39, 41-46].

Aryl and alkyl radicals of different length, aminogroups, thiols, carboxylic acid and other variable functionalities were successfully attached on the surface of PS as well as Si QDs by this approach. Differently from organosilicon compounds, the hydrosilylation on the surface of $\mathrm{Si}$ nanostructures does not require metalocomplex catalysts such as $\mathrm{H}_{2} \mathrm{PtCl}_{6}$; the $\mathrm{Si}_{4-\mathrm{x}} \mathrm{SiH}_{\mathrm{x}}$ groups can efficiently be activated to hydrosilylation by temperature (approx. $130{ }^{\circ} \mathrm{C}$ ), visible light or Lewis acid catalysts [39, 44-46]. As an alternative to hydrosilylation, covalently attached organic layers can be formed on the porous $\mathrm{Si}$ surfaces under treatment with Grignard and alkyl- or aryllithium reagents, which is considered in the reviews $[41,47]$. An interaction of surface $\mathrm{SiH}_{\mathrm{x}}$ groups with alcohols at elevated temperature resulted in alkoxy-coated $\mathrm{Si}$ particles [1, 48]. In general, alkyl coated Si QDs demonstrate superior qualities, such as better oxidation and hydrolytic stability as well as PL efficiency, comparing to unmodified $\mathrm{SiH}_{\mathrm{x}}$ coated QDs [9].

In [49] the Si QDs with alkyl passivation of the surface were obtained through mechanical milling of $\mathrm{Si}$ wafers in a reactive liquid medium like alkynes and alkenes under an inert atmosphere. The reaction of the terminal triple or double bond with the reactive $\mathrm{Si}-\mathrm{Si}$ and silicon surface radicals results in the formation of covalent $\mathrm{Si}-\mathrm{C}$ bonds, which are preventing further oxidation of the silicon surface. This cycloaddition of unsaturated hydrocarbons resulted in organic passivated $\mathrm{Si}$ QDs. The milling in monofunctionalized organic liquids forms Si QDs that are soluble exclusively in organic solvents.

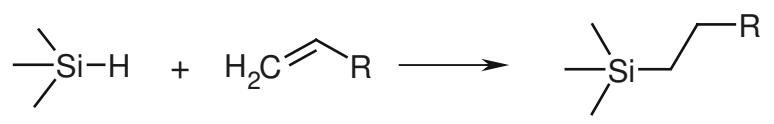

Scheme 1 Hydrosilylation on the surface of Si nanostructures 


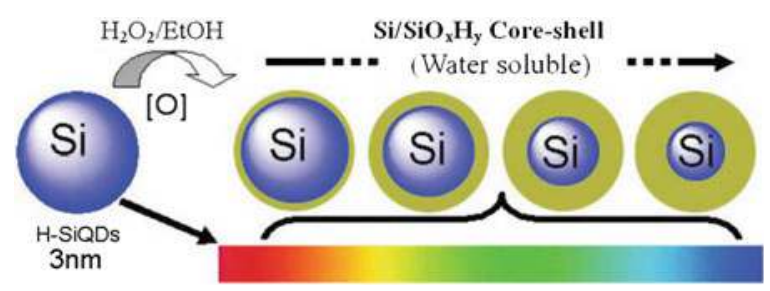

Fig. $83 \mathrm{~nm} \mathrm{H}-\mathrm{SiQDs}$ are oxidized in $\mathrm{EtOH}-\mathrm{H}_{2} \mathrm{O}_{2}$; emission of the oxidized SiQDs ranges from salmon pink to blue (from [51])

Very stable and bright emitting amine-terminated Si QDs with different alkyl chain lengths between the Si core and amine end-group were synthesized in [50]. The obtained Si QDs have a spherical shape and homogeneous size distribution $(1.6 \mathrm{~nm})$. Their emission can be tuned from the UV to the blue spectral region, in a controllable fashion, by only changing the alkyl spacer length. The emission quantum yields are $12 \%$ for all synthesized Si QDs. Excited state lifetimes are in the ns range and point to a direct band gap excitation. $\mathrm{NH}_{2}$-terminated $\mathrm{Si}$ QDs exhibit an exceptional stability over a wide $\mathrm{pH}$ range (1-13) and high temperatures $\left(120{ }^{\circ} \mathrm{C}\right)$.

Lee and co-workers recently presented an $\mathrm{EtOH} / \mathrm{H}_{2} \mathrm{O}_{2}$-assisted oxidation method to synthesize water-dispersed $\mathrm{Si} / \mathrm{SiO}_{\mathrm{x}} \mathrm{H}_{\mathrm{y}}$ core/shell QDs with a $\mathrm{Si}$ core of different controlled diameters [51]. Significantly, this method allows for fine tuning emission wavelengths of QDs, producing seven luminescent colors from blue to red, the fluorescent silicon nanospheres ( $\mathrm{Si} N \mathrm{NSs}$ ) containing several hundreds of SiQDs (Fig. 8). The as-prepared nanospheres possess excellent aqueous dispersibility, strong fluorescence (quantum yield: $\sim 15 \%$ ), robust photo-stability and favorable biocompatibility. They developed a new kind of water-dispersed oxidized SiNSs (O-SiNSs) prepared via thermal oxidation of the precursor SiNSs $[52,53]$. The quantum yield of the $\mathrm{O}-\mathrm{SiNSs}$ was dramatically increased to as high as $25 \%$. More significantly, $\mathrm{O}-\mathrm{SiNSs}$ are stable under high-power UV irradiation and in acidic-to-basic environments covering $\mathrm{pH}=2-12$. This extremely high $\mathrm{pH}$ stability leads to facile conjugation of nanospheres with antibodies, resulting in brightly luminescent silicon bioconjugates for immunofluorescent bioimaging (Fig. 9).

A production of stable silicon QDs with various surface functionalities through microwave-assisted hydrosilylation of hydride-terminated silicon QDs in the presence of various reactive compounds (decene, undecylenyl alcohol, and undecenoic acid) are considered in [54]. Reagents were selected from bifunctional compounds. One functional group should be the $\mathrm{C}=\mathrm{C}$ which is involved in the hydrosilylation process and the other group could bear any other functionality to enable widespread applications of SiQDs.

A significant enhancement of the PL efficiency is observed for aqueous suspensions of PS particles coated by bioresorbable polymers, i.e., polylacticco-glycolic acid (PLGA) and polyvinyl alcohol (PVA). The inner hydrophobic 
(a)

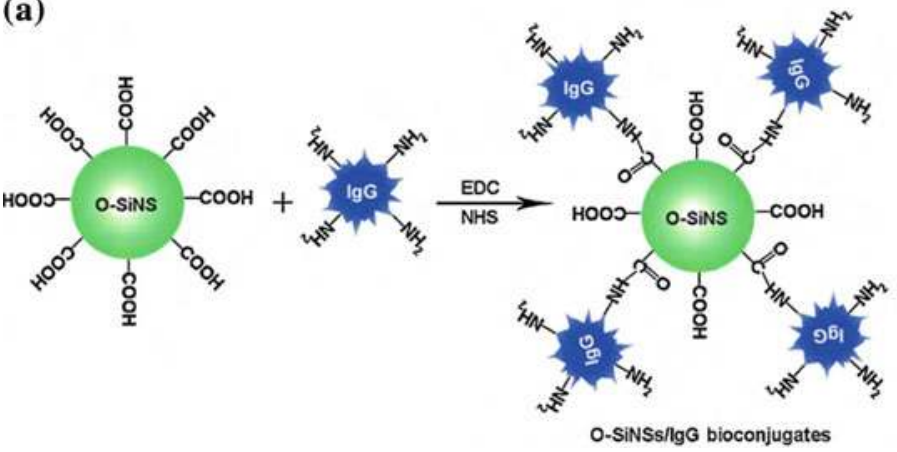

(b)

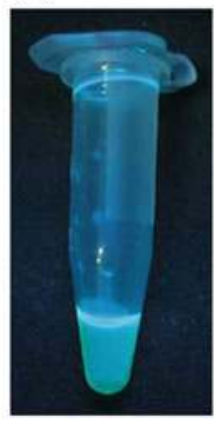

Fig. 9 a Schematic illustration of silicon nanospheres conjugating with goat-anti-mouse IgG. The carboxylic acid groups of nanospheres readily reacted with the amino groups of IgG by using EDC and NHS as zero-length cross-linkers (Figure is not to scale). b Optical micrographs of the prepared silicon bioconjugates under UV $(365 \mathrm{~nm})$ irradiation. The prepared bioconjugates preserve stable and bright fluorescent intensity for over 1 month (right) (from [53])

PLGA layer protects the QDs from the reaction with water, while the outer PVA layer makes the QDs hydrophilic [55]. UV-induced graft polymerization of acrylic acid on the surface of silicon nanoparticles was used to prepare a stable aqueous luminescent silicon QDs solution. By grafting a water-soluble polymer on the particle surface, the dispersions in water of the silicon nanoparticles became very stable and clear aqueous solutions could be obtained as in [56]. Hydrogen-capped silicon QDs with strong blue PL were synthesized by the metathesis reaction of sodium silicide, $\mathrm{NaSi}$, with $\mathrm{NH}_{4} \mathrm{Br}$. The hydrogen-capped $\mathrm{Si} \mathrm{QDs}$ were further terminated with octyl groups and then coated with a polymer to render them watersoluble [57]. Silicon QDs were prepared and functionalized with alkene-terminated poly (ethylene oxide) to impart amphiphilic solution properties to the particles [58]. The alkyl-passivated $\mathrm{Si}$ nanocolloids were obtained via thermally-initiated hydrosilylation of the hydrogenated Si nanoparticles, formed by electrochemical etching of Si wafer, with 1-undecene [59].

The carboxylic acid functionalized Si QDs (with the using of short alkyl chain organic peroxide, succinic acid peroxide) were applied for HeLa cells imaging [60] in several emission ranges. HeLa or heLa cell, is an immortalized cell type used in scientific research in vitro. The HeLa cells treated the carboxylic acid terminated Si QDs demonstrate the fluorescence with wide emission spectra arising from Si QDs (Fig. 10b-d). The bright blue fluorescence $(450 \mathrm{~nm})$ from the Si QDs is distributed uniformly and shows that the Si QDs were taken up into the cytoplasm (Fig. 10b). Remarkably, when the image for the $515 \mathrm{~nm}$ channel was collected, a bright green fluorescence from the internalized Si-QDs was clearly observed from the robust optical signal of the cells (Fig. 10c). Red fluorescence from the internalized Si QDs was also observed for the $605 \mathrm{~nm}$ channel (Fig. 10d). This behavior indicates that it might be possible to use hydrophilic Si QDs as chromophores for biological fluorescence imaging. 

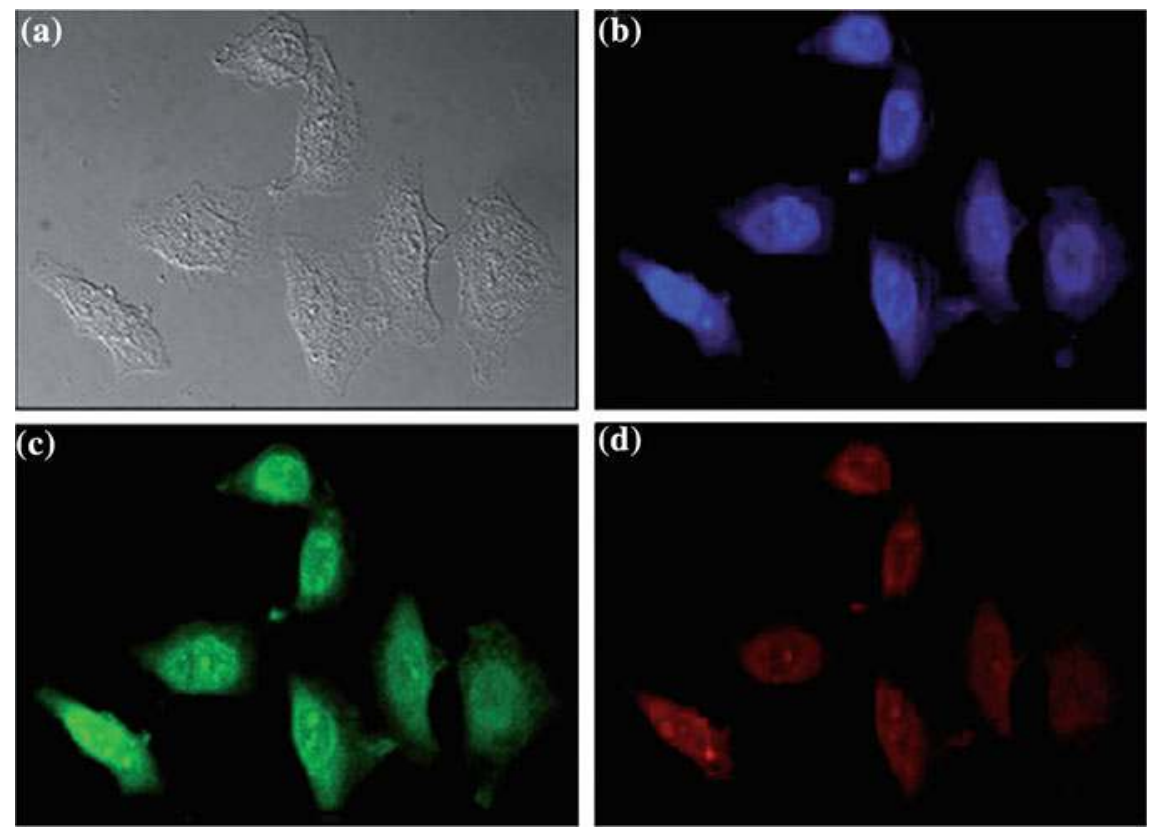

Fig. 10 Confocal microscopic visualisation of HeLa cells treated with carboxylic acid terminated Si QDs collected at different channels: a bright field image; and luminescence images collected at: b $450 \mathrm{~nm}$, c $515 \mathrm{~nm}$, and d $605 \mathrm{~nm}$ (from [60])

Application of functionalized luminescent Si QDs for bioimaging of tumors are considered in $[18,61,62]$. The micelle encapsulated SiQDs were injected intravenously into a Balb $\mathrm{C}$ mouse which was then sacrificed after $24 \mathrm{~h}$. The mouse was dissected and the organs were imaged to observe where the SiQDs were concentrating in the body (Fig. 11). The QDs concentrated preferentially in the spleen with some seen in the liver. The particles are not seen in the heart, lungs, kidneys, or the brain [62].

\section{Fabrication and PL Properties of Colloidal Solutions with SiCQDs}

Luminescent properties of silicon carbide $(\mathrm{SiC})$ nanostructures have been extensively studied during about last 15 years. In comparison to extremely weak PL of bulk $\mathrm{SiC}$ substrates at room temperature, PL intensity of the $\mathrm{SiC}$ nanostructures with dimensions $<10 \mathrm{~nm}$ is significantly enhanced [63]. Particularly, room temperature PL of porous SiC nanostructures obtained by electrochemical etching has received a special attention from scientists. Radiative recombinations via surface states and impurity levels have been discussed in literature as main mechanisms of the observed PL signals coming from the SiC nanostructures [64, 65]. In [66] it was 


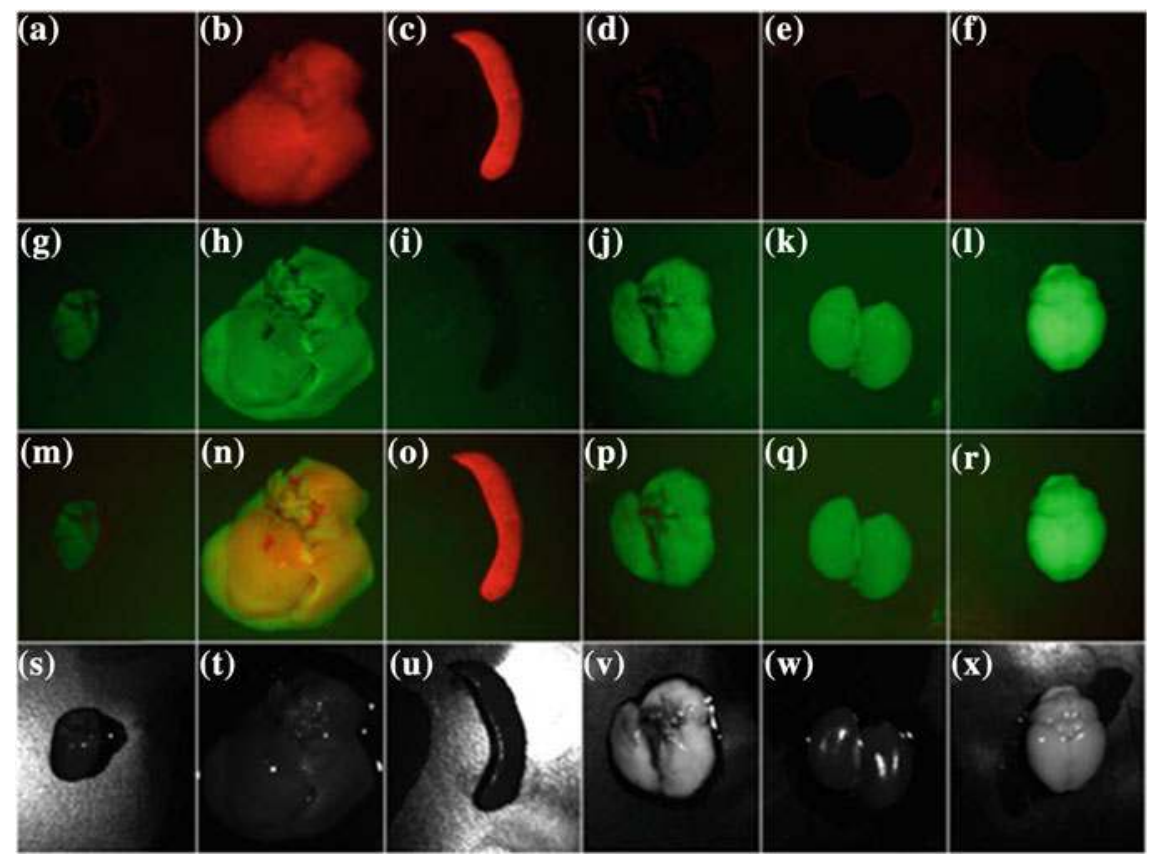

Fig. 11 Images of organs of a Balb $C$ mouse $24 \mathrm{~h}$ after injection of the Si QDs. A, G, M, S: Heart B, H, NN, T: Liver C, I, O, U: Spleen D, J, P, V: Lungs E, K, Q, W: Kidneys F, L, R, X: Brain. Top Row Fluorescence; Second Row Autofluorescence; Third Row Overlay; Fourth Row White light picture (from [62])

reported about ultraviolet PL from SiC nanoparticles with dimensions below $3 \mathrm{~nm}$, which were extracted from a porous layer formed by electrochemical etching. In particular, quantum confinement effect of photogenerated charge carriers was discussed by the authors to explain an important PL signal detected at energies higher than $3 \mathrm{eV}$. In addition, it has been also shown that when the non-radiative surface states were efficiently passivated by solvent molecules and concentration of the nanoparticles in the solutions was sufficiently low reducing considerably physical interactions between the nanoparticles, significant above-gap PL spectral tails due to recombination of quantum confined photoexcited carriers could be clearly seen [67]. Several years ago, it has been reported on experimental evidence of quantum confinement effect in the PL spectra of colloidal suspensions of SiC nanoparticles with cubic crystalline symmetry (3C-polytype) obtained by an ultrasonic treatment of porous $3 \mathrm{C}-\mathrm{SiC}$ layer in various solvents $[68,69]$. As the excitation wavelength was increased, the colloidal nanocrystals were found to give a strong above-gap emission band whose maximum was redshifted in the range from 2.8 to $2.2 \mathrm{eV}$. At the same time, as expected by the quantum confinement model, the emission intensity rises up to a maximum before decreasing which correlates to the size distribution supported by TEM measurements. 
The method of forming SiC QDs obtained by electrochemical etching of bulk substrates of 3C polytype was described in [70, 71]. Firstly, 3C-SiC nano-porous layer was formed by means of electrochemical anodization of a low resistivity grade $(<1 \Omega \mathrm{cm})$ bulk $3 \mathrm{C}-\mathrm{SiC}$ polycrystalline wafer. The etching process took place for $2-3 \mathrm{~h}$ at a current density of $25 \mathrm{~mA} / \mathrm{cm}^{2}$ using a $1: 1 \mathrm{HF}(50 \%) /$ ethanol electrolyte. After the etching, a highly porous network constituted by numerous interconnected $3 \mathrm{C}-\mathrm{SiC}$ nanocrystals was formed. The ultra-porous layer was washed with water, naturally dried in ambient air and then removed from the wafer. An intense mechanical dry grinding of the formed free nano-porous layer transformed it into a nano-powder state. The as-prepared 3C-SiC nanopowder can be dispersed in various polar solutions. To change surface charges, the suspended QDs are treated in different surfactants like cetyl-tri-methyl-ammonium bromide (CTMA) and sodium lauryl sulphate (SLS) which are added to the colloidal solutions to communicate positive and negative surface charges to the QDs, respectively.

FTIR spectra of the $\mathrm{SiC}$ QDs recorded in transmittance (pellet in $\mathrm{KBr}$ ) and diffuse reflectance modes, are presented in Fig. 12. The assignment of the bands coincides in general with results obtained for porous $6 \mathrm{H}-\mathrm{SiC}$ and $3 \mathrm{C}-\mathrm{SiC}$ [70-72]. Wide $v(\mathrm{OH})$ band centred at about $3,500 \mathrm{~cm}^{-1}$ corresponds to the adsorbed water molecules as well as to $\mathrm{C}-\mathrm{OH}$ and $\mathrm{Si}-\mathrm{OH}$ groups. Multiple bands at 2,985, 2,943 and $2,914 \mathrm{~cm}^{-1}\left(v\left(\mathrm{CH}_{\mathrm{x}}\right)\right)$ and $1,469,1,450$ and $1,375 \delta\left(\mathrm{CH}_{\mathrm{x}}\right)$ indicate on presence of different types of aliphatic $\mathrm{CH}_{\mathrm{x}}$ groups in the $\mathrm{SiC}$ QDs. Intense $v(\mathrm{C}=\mathrm{O})$ band at $1,743 \mathrm{~cm}^{-1}$ which is clearly seen in the spectrum of $\mathrm{SiC}$ sample, can be assigned not only to the presence of carboxylic acid groups, but also to their esters such as $-\mathrm{COOC}_{2} \mathrm{H}_{5}$, because the position of the band is shifted to higher wavenumbers comparing to common spectra of carboxylic acids (usually the $\mathrm{C}=\mathrm{O}$ band of hydrogen bonded $-\mathrm{COOH}$ groups is observed at $1,700-1,725 \mathrm{~cm}^{-1}$, however for $-\mathrm{COOH}$ group without $\mathrm{H}$-bonds it can be found at $1,770 \mathrm{~cm}^{-1}$ ). Wide band at centred at $1,213 \mathrm{~cm}^{-1}$ probably appeared due to the combination of $v(\mathrm{C}-\mathrm{O})$ band of $-\mathrm{COOH}$ groups, $v(\mathrm{Si}-\mathrm{O})$ band and some lattice bands of $\mathrm{SiC}$.

Fig. 12 FTIR spectra (transmittance and diffuse reflectance) of palletized and ground $3 \mathrm{C}-\mathrm{SiC}$ samples (from [70])

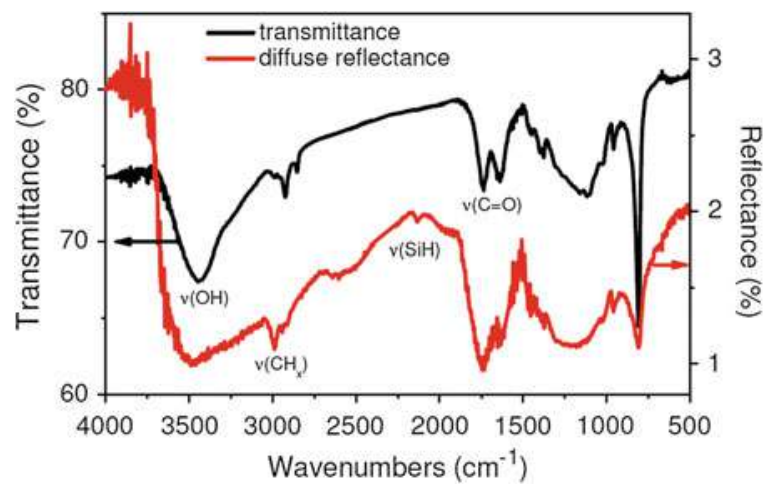


(a)

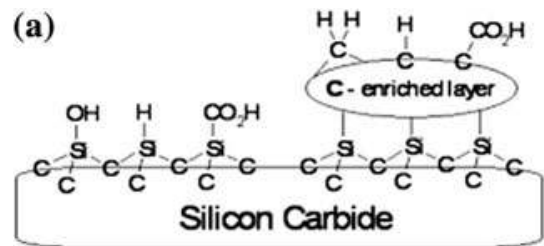

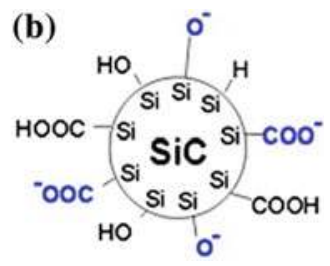

Fig. 13 Schematic representation of: a general surface chemistry and b surface charges of 3C$\mathrm{SiC}$ nanoparticles [70]

The surface groups of the 3C-SiC nano-powder are very similar to those of recently studied $6 \mathrm{H}-\mathrm{SiC}$ porous nanostructures and schematically represented by a scheme in Fig. 13a. According to [73], the 3C-SiC QDs surface contains carbonenriched layer appeared mainly due to the preferential removing of $\mathrm{Si}$ atoms during the electrochemically assisted nano-powder formation. Dissociation of the carboxylic $(\mathrm{Si}-\mathrm{COOH})$ and/or silanol $(\mathrm{Si}-\mathrm{OH})$ acid groups in polar solvents leads to appearance of negative electric charges at the nanoparticle surface as it is illustrated by scheme in Fig. 13b. In particular, these charges are responsible for extremely stable and optically homogeneous colloidal solutions obtained with the 3C-SiC QDs dispersed in solvents.

Electrostatic screening of the radiative band gap states by highly polar solvent media leads to a blue shift and a decrease in the width at half maximum of the PL spectra of the QDs. As for the surface charges, they govern band bending slope and thus influence strongly the radiative transitions via energy states in the band gap.

Transmission electron microscopy (TEM) image of the spherical-like SiC QDs is given in Fig. 14a. An example of a daylight photo of the centrifuged optically homogeneous colloidal suspension of the $3 \mathrm{C}-\mathrm{SiC}$ is shown by the inset in Fig. 14a. Typical size distribution of the 3C-SiC QDs is presented in Fig. 14b. As one can see, the majority of the QDs dimensions are found to be below $5 \mathrm{~nm}$ with the most probable size value being around $2.5 \mathrm{~nm}$. The inset in Fig. 14b shows typical PL spectrum of the 3C-SiC QDs dispersed in aqueous solutions under UV excitation. Since the mean size value of the SiC QDs are smaller then the Bohr's diameter of the exciton in bulk $\mathrm{SiC}$ substrate $(\sim 5.4 \mathrm{~nm})$, they exhibit highly efficient luminescence with energies higher than bandgap energy of bulk $\mathrm{SiC}$ due to spatial and quantum confinement effects [71].

Well defined spherical colloidal cubic SiC QDs with average diameter of $5 \mathrm{~nm}$ were synthesized using the reactive bonding and wet chemical etching method in $[74,75]$. These QDs show strong violet-blue PL emission. ATR-IR measurements revealed the surface structure of the $\mathrm{SiC}$ QDs which consists of $\mathrm{Si}-\mathrm{O}-\mathrm{Si}, \mathrm{C}-\mathrm{O}-\mathrm{C}$, $\mathrm{CH}, \mathrm{COOH}$, and $\mathrm{COO}$-surface terminations as for electrochemically prepared QDs.

There are only few reports on surface functionalization of $\mathrm{SiC}$ nanoparticles $[4,75-79]$. Polymerization of the conducting polyaniline in the presence of camphorsulfonic acid and $\mathrm{SiC}$ nanoparticles results in the formation of polyanilinecamphorsulfonic acid shell with a thickness in the range from $0.5 \mathrm{~nm}$ to a few 

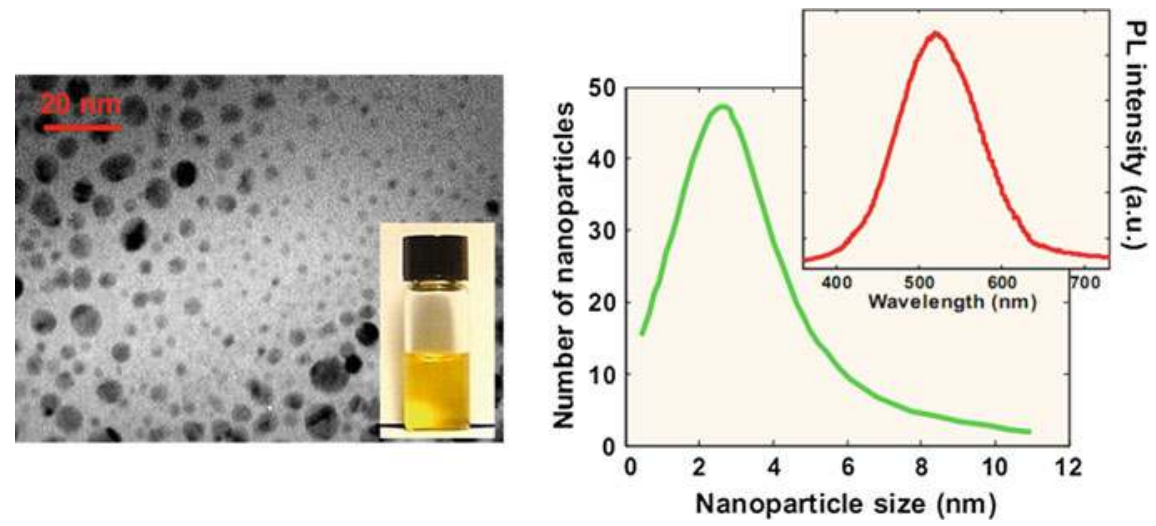

Fig. 14 Left The general TEM image of the SiC QDs. Inset shows a colloidal solution with the dispersed SiC QDs; Right size distribution of the SiC QDs. Inset shows a typical PL spectrum of the colloidal 3C-SiC QDs (from [81])

nanometers at the surface of SiC nanocrystals [79]. Zhang et al. [76] reports on PL and light reabsorption in the $\mathrm{SiC}$ QDs embedded in the binary poly(allylamine hydrochloride)-sodium poly(styrene sulfonate) polyelectrolytes solid matrix. The emission maximum wavelength can be tuned over a wide blue-violet spectral region indicating the quantum confinement as the origin of light emission.

\section{SiC QDs as Fluorescent Bio-Labels}

The highly luminescent 3C-SiC QDs was successfully explored as fluorescent agents for living cell imaging. By using fluorescent microscope we studied the cells of different plants, mouse fibroblast, healthy and cancer epithelial human cells with SiC QDs [8, 71, 80, 81]. Covalent grafting of amino groups onto the carboxylic acid functionalities, naturally covering the surface of fluorescent nanoparticles produced from silicon carbide, allowed tuning of their surface charge from negative to highly positive (Fig. 15). Grafting of aminogroups was performed by the reaction of $\mathrm{SiC}$ QDs surface carboxylic acid groups with ethylenediamine (En, $\mathrm{H}_{2} \mathrm{~N}-\mathrm{CH}_{2} \mathrm{CH}_{2}-\mathrm{NH}_{2}$ ) (Fig. 15).

Incubating 3T3-L1 fibroblast cells with differently charged SiC QDs demonstrates the crucial role of the charge in cell fluorescent targeting [71]. Negatively charged SiC QDs concentrate inside the cell nuclei. Close to neutrally charged SiC QDs are present in both cytoplasm and nuclei while positively charged SiC QDs are present only in the cytoplasm and are not able to move inside the nuclei (Fig. 16). This effect opens the door for the use of SiC QDs for easy and fast visualization of long-lasting biological processes taking place in the cell cytosol or nucleus as well as providing a new long-term cell imaging tool. Moreover, here we 

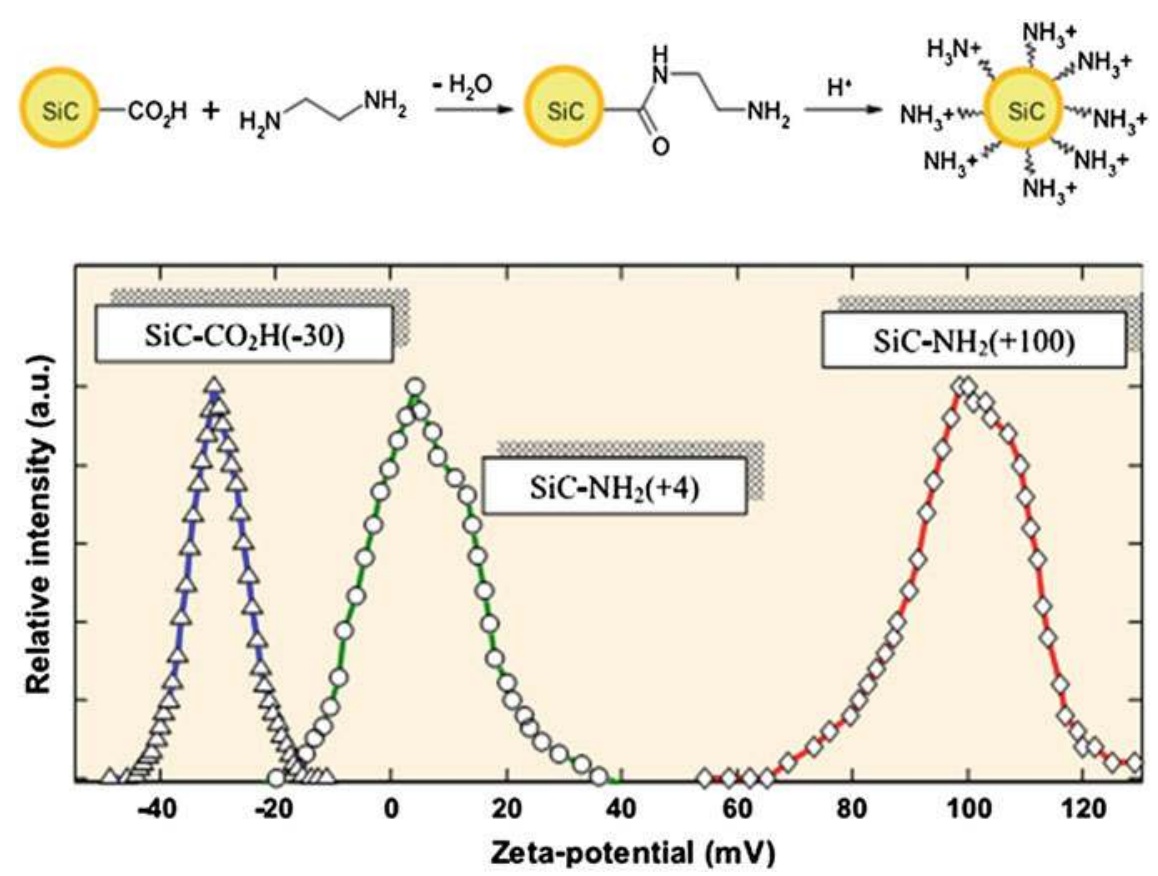

Fig. 15 Top Grafting of amino groups on the surface of as-prepared SiC QDs; Bottom Zetapotential measurements performed on colloidal solutions of $\mathrm{SiC}-\mathrm{CO}_{2} \mathrm{H}(-30), \mathrm{SiC}-\mathrm{NH}_{2}(+4)$ and $\mathrm{SiC}-\mathrm{NH}_{2}(+100)$ (from [71])

have shown that the interaction between charged QDs and nuclear pore complex plays an essential role in their penetration into the nuclei. The importance of electrostatic interactions was more recently strengthened by authors studying the molecular structure of the yeast nuclear pore complex (NPC) and the translocation of model particles [82].

The uptake of QDs and its intra-nuclei concentration is dependant to cell proliferation (Fig. 17). This has been shown by two different ways, first in healthy cells and second in cancer cells [81]. In healthy SG cells (a human immortalized gingival epithelioid cell line), the labeling is altered by the state of confluence, at confluence the labeling is low and absent in the nuclei (c) while it is strong and present in the nuclei when cells divide (a and b). In cancer cells HSC-2 (a human oral squamous carcinoma line), that proliferate even at confluence, the labeling is not influence by confluence ( $\mathrm{d}$, e and f). Although the mechanism linking intranuclear accumulation of SiC QDs and cell proliferation has not been yet identified, this observation is important for at least two reasons. Firstly, it brings evidence of a specificity of $\mathrm{SiC}$ QDs to be uptaken by proliferating cells that are promising to give specificity for cancer treatment or drug delivery with $\mathrm{SiC}$ QDs. 


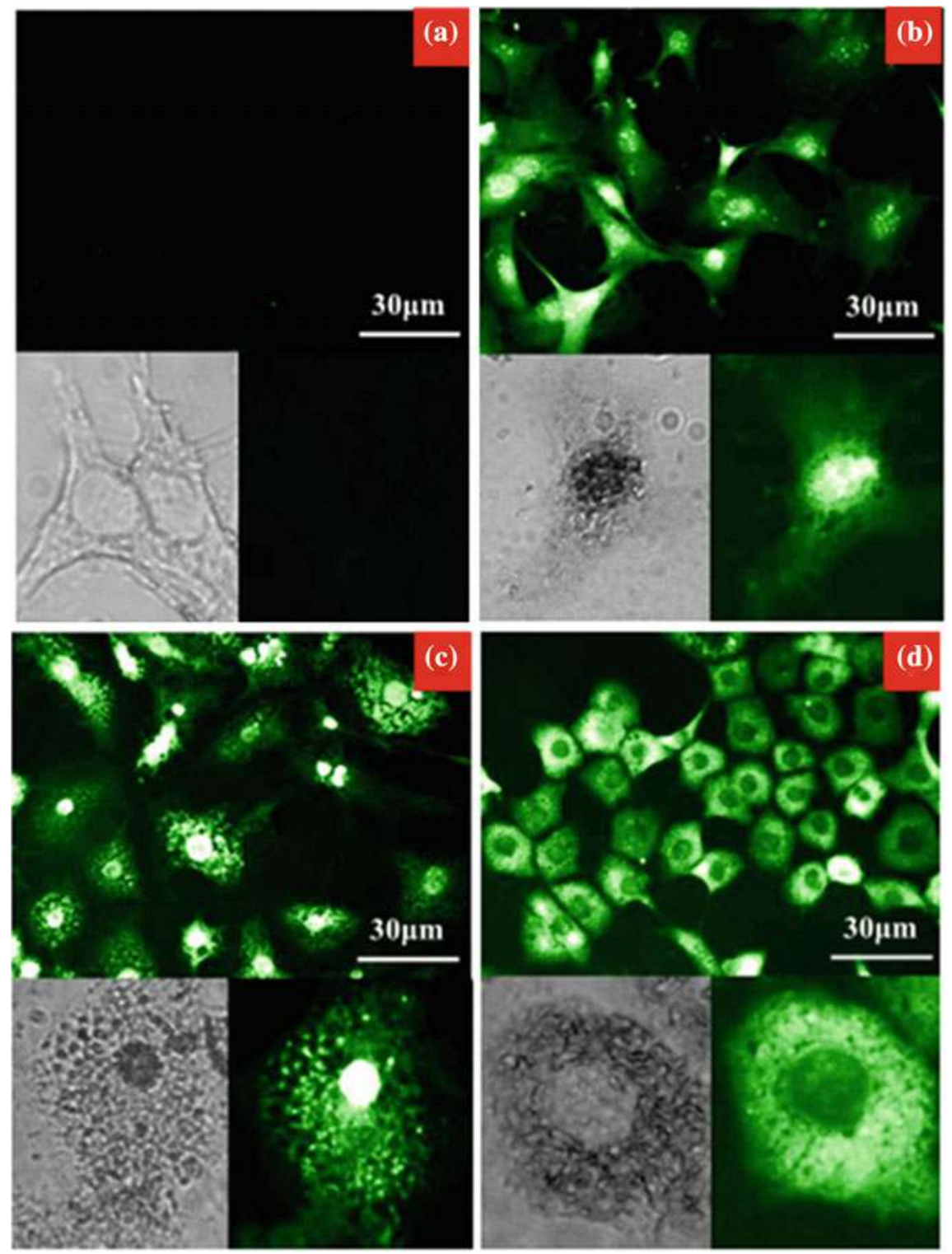

Fig. 16 Fluorescence and visible microscopy images of 3T3-L1 cells: a without SiC QDs; b labeled with negatively charged $\mathrm{SiC}-\mathrm{CO}_{2} \mathrm{H}(-30)$ QDs; c labeled with quasineutral $\mathrm{SiC}-\mathrm{NH}_{2}$ (+4) QDs and d labeled with positively charged $\mathrm{SiC}-\mathrm{NH}_{2}$ (+100) QDs (from [71])

Secondly, a majority of studies on QDs are done on proliferating cells, according to the present results, the behaviour of QDs may be not the same for non confluent (proliferating) and confluent (non proliferating) cells. 

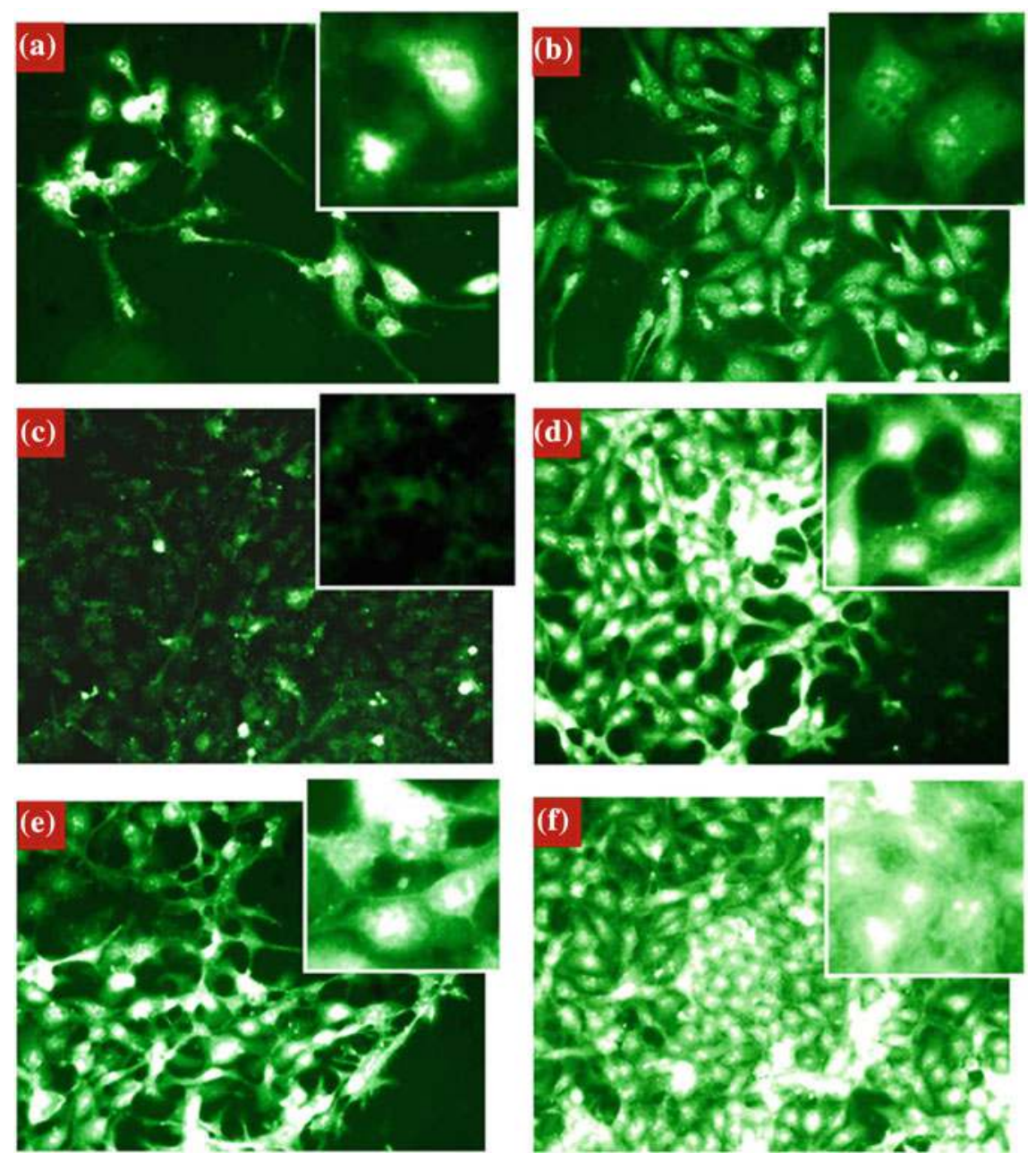

Fig. 17 Fluorescence microscopy images of SG $(\mathbf{a}, \mathbf{b}, \mathbf{c})$ and HSC-2 (d, e, f) cells labeled by SiC QDs: (a), (d) low confluence (b), (e) intermediate confluence, (c), (f) total confluence (from [81])

To test the cytotoxic potential of SiC QDs, we chose two oral squamous carcinoma and one immortalized oral epithelioid lines. Like the two cancer lines, the control cells we used possess a high growth rate and are used as a control in comparison to HSC-2 cells [83]. Higher concentrations of $\mathrm{SiC}$ QDs and longer exposure time are required to reduce $\mathrm{S}-\mathrm{G}$ proliferation when compared to both human and murine tumoral cells. The differential toxicity of SiC QDs against rapidly dividing cancer cells suggests their potential use as antitumoral agents. The precise mechanism(s) of action of $\mathrm{SiC}$ QDs in inhibiting cell proliferation remains to be investigated. We considered the possibility of using QDs for antitumor 
therapy. When $\mathrm{SiC}$ QDs concentration of $2 \mathrm{mg} / \mathrm{mL}$ kills $100 \%$ of the cancer cells HSC-2 is already at 6:00 incubation and almost no effect on the survival of the culture of healthy cells that have stopped cell division through a mechanism of contact inhibition. This means that toxic effects, as well as the total amount of nanoparticles in the cell decreases dramatically when the cell stops proliferation (division) [8].

SiC QDs have, however, few disadvantages preventing their use in complex bio-imaging applications. This includes low quantum yield and rather broad emission band, which makes multicolour imaging difficult. Low quantum yield also influences concentration at which labeling effect is detectable. Therefore, to compete with usual fluorophores, a strong PL enhancement of SiC QDs may be ensured by their nearfield coupling with multipolar plasmons [84]. In order to achieve a high PL enhancement factors, an approach based on: (1) localization of $\mathrm{SiC}$ QDs in the vicinity of randomly arranged silver (Ag) nanoparticles (NPs) chemically formed on silicon nitride $\left(\mathrm{SiN}_{\mathrm{X}}\right)$ /glass substrates and (2) careful tuning of the multipolar plasmon bands of the nanoparticles to overlap the excitation and emission spectral bands of SiC QDs, has been developed.

Fluorescence images of fibroblast cells on glass and plasmonic substrates with or without SiC QDs can be seen in Fig. 18. All images were obtained under the same observation conditions in terms of excitation (UV/violet excitation band $(\lambda=350-460 \mathrm{~nm})$ and an observation spectral range corresponding to the wavelengths $\lambda>470 \mathrm{~nm}$ ) and acquisition time. Natural fluorescence of the cells grown on the usual glass cover slip substrates is too weak to be observed in such experimental conditions (Fig. 18a). On the other hand, the cells grown on the glass substrates and labeled with the SiC QDs can be better seen in Fig. 18b. Strong auto-fluorescence enhancement of the fibroblast cells grown onto the nano-Ag/ $\mathrm{SiN}_{\mathrm{X}} /$ glass substrates is shown in Fig. 18c. This label-free natural green cell autofluorescence is significantly increased in comparison with the cells grown on a simple glass substrate (Fig. 18a). The cells with the up-taken SiC QDs grown onto the nano- $\mathrm{Ag} / \mathrm{SiN}_{\mathrm{X}} /$ glass substrates show a drastic fluorescence enhancement (Fig. 18d) in comparison to the cells containing the same quantity of the SiC QDs and grown on a usually-used glass cover slips (Fig. 18b).

Different mechanisms can be responsible for the observed fluorescence enhancement of the cells. Firstly, the localized plasmons appearing in the Ag NPs leads to an increase of excitation/absorption and photostimulated auto-emission of the cell membranes due to their close proximity to the Ag NPs. The fluorescence enhancement can be only observable when the plasmons are localized in very close vicinity to the cell membrane. Moreover, the cell membrane thickness is estimated to be around a few nanometers which allows plasmon-induced PL enhancement of the NPs up-taken by the cells and localized near the membrane after the dehydration and the subsequent fixation of the cells on the plasmonic nano- $\mathrm{Ag} / \mathrm{SiN}_{\mathrm{X}} / \mathrm{glass}$ substrate. All these factors can explain the detected enhancement of cell auto-fluorescence and PL of the up-taken SiC QDs (see Fig. 18c and d, respectively). 

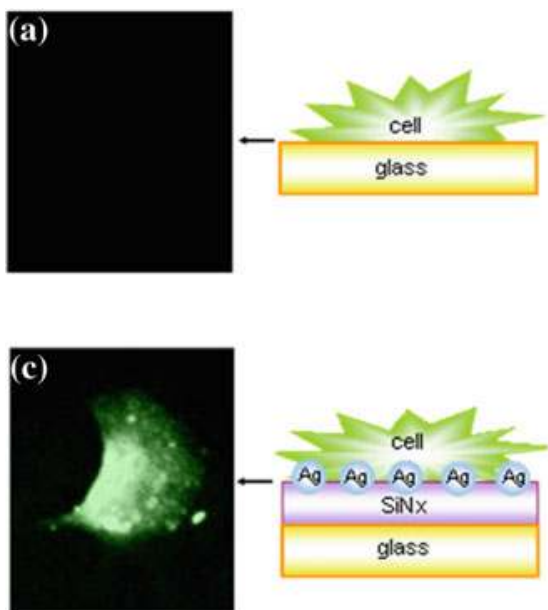

(b)

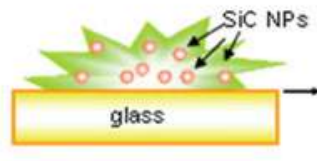

(d)
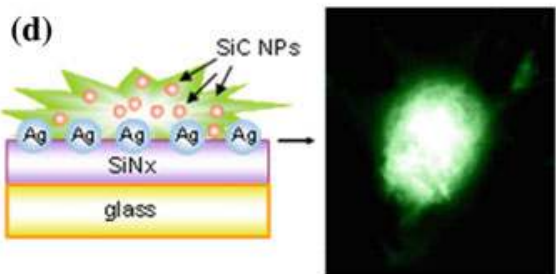

Fig. 18 Sample schematics and corresponding fluorescent images of fibroblast cells: a on glass substrate, b labelled with the $\mathrm{SiC}$ QDs on glass substrate, $\mathbf{c}$ on nano- $\mathrm{Ag} / \mathrm{SiN} \mathrm{N}_{\mathrm{X}} /$ glass substrate, d labelled with the $\mathrm{SiC}$ NPs on nano-Ag/SiNX/glass substrate

Secondly, the cell labeling with the SiC QDs can induce modification of the local effective dielectric constant which will lead to a better near-filed coupling (in terms of spectral overlap) with the localized plasmon modes under the same excitation conditions. In addition, the higher values of the local dielectric constant will also ensure the higher intensities of the plasmon-induced local electric field penetrating deeper inside the labelled cells. Finally, a certain degree of the excitation scattering within the nanostructured area and inside the cells may explain general PL enhancement taking place in the whole cell volume. Moreover, the use of a UV/violet filter selecting the exciting photons from the relatively large spectral range $(\lambda=350-460 \mathrm{~nm})$ of a white lamp leads to a simultaneous photoexcitation of a wide absorptive part of the extinction spectra, provoking significant increase of the absorption cross-sections of numerous cell fluorescent agents as well as of the big number of the $\mathrm{SiC}$ QDs with various sizes.

In addition, the auto-fluorescence cell signal and PL of the SiC QDs incorporated inside the cells (detected in the spectral range $\lambda>470 \mathrm{~nm}$ ) are strongly enhanced by near-field interaction with the coupled dipole plasmon modes, as it is discussed in details in [84].

\section{Conclusion}

This chapter focuses on the preparation of colloidal solutions of $\mathrm{Si}$ and $\mathrm{SiC}$ QDs by the method of electrochemical etching of bulk $\mathrm{Si}$ and $3 \mathrm{C}-\mathrm{SiC}$. It was shown that a broad size distribution of crystalline $\mathrm{Si}$ and $\mathrm{SiC}$ QDs are obtained. It is worth 
noting that the dimensions the dimensions of the Si QDs undergone filtering in colloidal solution vary discretely with a radius quantum equal to $0.12 \mathrm{~nm}$. Existing of this quantum may correspond to step-like increasing of Si QDs radius on one new shell at the surface of Si QDs. The formed QDs show intense luminescence in visual region that is promising for fluorescent labeling of biomaterials. However, one of the major drawbacks of SiQDs for application for bioimaging is instability over time in water or buffer solutions. To overcome this drawback the several methods of surface functionalization are proposed and discussed. From the other side, the SiC QDs are stable in water solutions and do not require supplementary surface functionalisation for bioimaging. A strong fluorescence from the SiC QDs, which undoubtedly penetrate into the cell, has been observed. The studying of health and cancer cells using SiC QDs show that simple modification of surface charge of QDs give strong opportunity to target the same QDs in intracellular space with their preferential localisation inside or outside the cell nucleus. Electrostatic interaction between QDs and positively charged chromatin gives platform to completely switch-open penetration or it blocking corresponding to the surface charge of QDs that plays role of key to open/close nucleus membrane doors. These effects open wide perspectives for understanding and discovering nucleus transport mechanisms and give possibility for their bright imaging. Moreover, the uptake of QDs and its intra-nuclei concentration is strongly dependant on cell proliferation.

\section{References}

1. Kumar, V. (ed.): Nanosilicon. Elsevier Ltd, Amsterdam (2007)

2. Geszke-Moritz, M., Moritz, M.: Quantum dots as versatile probes in medical sciences: Synthesis, modification and properties. Mater. Sci. Eng., C 33, 1008-1021 (2013)

3. Michalet, X., Pinaud, F.F., Bentolila, L.A., Tsay, J.M., Doose, S., Li, J.J., Sundaresan, G., Wu, A.M., Gambhir, S.S., Weiss, S.: Quantum dots for live cells, in vivo imaging, and diagnostics. Science 307, 538-544 (2005)

4. Fan, J., Chu, P.K.: Group IV nanoparticles: synthesis, properties, and biological applications. Small 6, 2080-2098 (2010)

5. Alivisatos, A.P.: The use of nanocrystals in biological detection. Nat. Biotechnol. 22, 47-52 (2004)

6. Parak, W.J., Pellegrino, T., Plank, C.: Labelling of cells with quantum dots. Nanotechnology 16, R9-R25 (2005)

7. Bonacina, L.: Nonlinear nanomedecine: harmonic nanoparticles toward targeted diagnosis and therapy. Mol. Pharm. 10, 783-792 (2013)

8. Bluet, J.-M., Botsoa, J., Zakharko, Y., Géloën, A., Alekseev, S., Marty, O., Mognetti, B., Patskovsky, S., Rioux, D., Lysenko, V.: SiC as a biocompatible marker for cell labeling, Chapter 11. In: Silicon Carbide Biotechnology, Saddow, S (ed) Elsevier Inc., pp. 327-429. 2012

9. Kang, Z., Liu, Y., Lee, S.-T.: Small-sized silicon nanoparticles: new nanolights and nanocatalysts. Nanoscale 3, 777-791 (2011)

10. Dabbousi, B.O., Rodriguez-Viejo, J., Mikulec, F.V., Heine, J.R., Mattoussi, H., Ober, R., Jensen, K.F., Bawendi, M.G.: CdSe-ZnS core-shell quantum dots: synthesis and characterization of a size series of highly luminescent nanocrystallites. J. Phys. Chem. B. 101, 9463-9475 (1997) 
11. Nozik, A.J.: Spectroscopy and hot electron relaxation dynamics in semiconductor quantum wells and quantum dots. Annu. Rev. Phys. Chem. 52, 193-231 (2001)

12. Giljohann, D.A., Mirkin, C.A.: Drivers of biodiagnostic development. Nature 462, 461-464 (2009)

13. Hines, M.A., Guyot-Sionnest, P.: Synthesis and characterization of strongly luminescing ZnS-capped CdSe nanocrystals. J. Phys. Chem. 100, 468-471 (1996)

14. Bruchez Jr, M., Moronne, M., Gin, P., Weiss, S., Alivisatos, A.P.: Semiconductor nanocrystals as fluorescent biological labels. Science 281, 2013-2016 (1998)

15. Derfus, A.M., Chan, W.C.W.: Bhatia SN, Probing the cytotoxicity of semiconductor quantum dots. Nano Lett. 4, 11-18 (2004)

16. Kirchner, C., Liedl, T., Kudera, S., Pellegrino, T., Munoz Javier, A., Gaub, H.E., Stölzle, S., Fertig, N., Parak, W.J.: Cytotoxicity of colloidal CdSe and CdSe/ZnS nanoparticles. Nano Lett. 5, 331-338 (2005)

17. Fojtik, A., Henglein, A.: Luminescent colloidal silicon particles. Chem. Phys. Lett. 221, 363-367 (1994)

18. Erogbogbo, F., Yong, K.-T., Roy, I., Hu, R., Law, W.-C., Zhao, W., Ding, H., Wu, F., Kumar, R., Swihart, M.T., Prasad, P.N. In Vivo Targeted Cancer Imaging, Sentinel Lymph Node Mapping and Multi-Channel Imaging with Biocompatible Silicon Nanocrystals, ACS NANO. 5, 413-423 (2011)

19. Knipping, J., Wiggers, H., Rellinghaus, B., Roth, P., Konjhodzic, D., Meier, C.: Synthesis of high purity silicon nanoparticles in a low pressure microwave reactor. J. Nanosci. Nanotechn. 4, 1039-1044 (2004)

20. Sankaran, R.M., Holunga, D., Flagan, R.C., Giapis, K.P.: Synthesis of blue luminescent si nanoparticles using atmospheric-pressure microdischarges. Nano Lett. 5, 537-541 (2005)

21. Rowsell, B.D., Veinot, J.G.C.: Reductive thermolysis of a heterocyclic precursor: a convenient method for preparing luminescent, surfactant-stabilized silicon nanoparticles. Nanotechnology 16, 732-736 (2005)

22. Baldwin, R.K., Pettigrew, K.A., Ratai, E., Augustine, M.P. Kauzlarich, S.M.: Solution reduction synthesis of surface stabilized silicon nanoparticles, Chem. Commun. 17, 1822-1823 (2002)

23. Zou, J., Baldwin, R.K., Pettigrew, K.A., Kauzlarich, S.M.: Solution synthesis of ultrastable luminescent siloxane-coated silicon nanoparticles. Nano Lett. 4, 1181-1186 (2004)

24. Rao, S., Sutin, J., Clegg, R., Gratton, E., Nayfeh, M.H., Habbal, S., Tsolakidis, A., Martin, R.M. Excited states of tetrahedral single-core Si29 nanoparticles. Phys. Rev. B . 69, art.205319 (2004)

25. Tanaka, A., Saito, R., Kamikake, T., Imamura, M., Yasuda, H.: Electronic structures and optical properties of butyl-passivated Si nanoparticles. Solid State Commun. 140, 400-403 (2006)

26. Lysenko, V., Onyskevych, V., Marty, O., Skryshevsky, V.A., Chevolot, Y., Bru-Chevallier, C.: Extraction of ultraviolet emitting silicon species from strongly hydrogenated nanoporous silicon, App. Phys. Let. 92, art.251910 (2008)

27. Lysenko, V., Bidault, F., Alekseev, S., Turpin, C., Geobaldo, F., Rivolo, P., Garrone, E., Zaitsev, V., Barbier, D.: Study of porous silicon nanostructures as hydrogen reservoirs. J. Phys. Chem. B. 109, 19711-19718 (2005)

28. Nychyporuk, T., Lysenko, V., Barbier, D. Fractal nature of porous silicon nanocrystallites, Phys. Rev. B. 71, art. 115402 (2005)

29. Serdiuk, T., Lysenko, V., Alekseev, S., Skryshevsky, V.A.: Size tuning of luminescent silicon nanoparticles with meso-porous silicon membranes. J. Colloid Interface Sci. 364, 65-70 (2011)

30. Serdiuk, T., Skryshevsky, V.A., Ivanov, I.I., Lysenko, V.: Storage of luminescent nanoparticles in porous silicon: Toward a solid state golden fleece. Mater. Lett. 65, 2514-2517 (2011) 
31. Belomoin, G., Therrien, J., Smith, A., Rao, S., Twesten, R., Chaieb, S., Nayfeh, M.H., Wagner, L., Mitas, L.: Observation of a magic discrete family of ultrabright Si nanoparticles, Appl. Phys. Lett. 80, art. 841 (2002)

32. Patrone, L., Nelson, D., Safarov, V.I., Sentis, M., Marine, W.: Photoluminescence of silicon nanoclusters with reduced size dispersion produced by laser ablation, J. Appl. Phys. 87, art. 3829 (2000)

33. Ledoux, G., Guillois, O., Porterat, D., Reynaud, C.: Photoluminescence properties of silicon nanocrystals as a function of their size. Phys. Rev. B. 62, 15942-15951 (2000)

34. Feng, Z.C., Tsu, R. (eds.): Porous Silicon. World Scientific, Singapore (1994)

35. Delerue, C., Allan, G., Lannoo, M.: Theoretical aspects of the luminescence of porous silicon. Phys. Rev. B. 48, 11024-11036 (1993)

36. Kang, Z.H., Tsang, C.H.A., Zhang, Z.D., Zhang, M.L., Wong, N.B., Zapien, J.A., Shan, Y.Y., Lee, S.T.: A polyoxometalate-assisted electrochemical method for silicon nanostructures preparation: from quantum dots to nanowires. J. Am. Chem. Soc. 129, 5326-5327 (2007)

37. Kang, Z.H., Tsang, C.H.A., Wong, N.B., Zhang, Z.D., Lee, S.T.: Silicon quantum dots: a general photocatalyst for reduction, decomposition, and selective oxidation reactions. J. Am. Chem. Soc. 129, 12090-12091 (2007)

38. Heinrich, J.L., Curtis, C.L., Credo, G.M., Kavanagh, K.L., Saylor, M.J.: Luminescent colloidal silicon suspensions from porous silicon. Science 255, 66-68 (1992)

39. Buriak, J.M., Allen, M.J.: Lewis acid mediated functionalization of porous silicon with substituted alkenes and alkynes. J. Am. Chem. Soc. 120, 1339-1340 (1998)

40. Manilov, A.I., Skryshevsky, V.A.: Hydrogen in porous silicon—a review. Mater. Sci. Eng., B 178, 942-955 (2013)

41. Anglin, E.J., Cheng, L., Freeman, W.R., Sailor, M.J.: Porous silicon in drug delivery devices and materials. Adv. Drug Deliv. Rev. 60, 1266-1277 (2008)

42. Boukherroub, R., Petit, A., Loupy, A., Chazalviel, J.N., Ozanam, F.: Microwave-assisted chemical functionalization of hydrogen-terminated porous silicon surfaces. J. Phys. Chem. B. 107, 13459-13462 (2003)

43. Wu, E.C., Park, J.-H., Park, J., Segal, E., Cunin, F., Sailor, M.J.: Oxidation-triggered release of fluorescent molecules or drugs from mesoporous Si microparticles. ACS Nano. 2, 2401-2409 (2008)

44. Stewart, M.P., Buriak, J.M.: Photopatterned hydrosilylation on porous silicon. Angew. Chem. Int. Ed. 37, 3257-3260 (1998)

45. Sam, S., Chazalviel, J.N., Gouget-Laemmel, A.C., Ozanam, F., Etcheberry, A., Gabouze, N.: Peptide immobilisation on porous silicon surface for metal ions detection. Nanoscale Res. Lett. 6, art.412 (2011)

46. Hua, F., Swihart, M.T., Ruckenstein, E.: Efficient surface grafting of luminescent silicon quantum dots by photoinitiated hydrosilylation. Langmuir 21, 6054-6062 (2005)

47. Ruizendaal, L., Pujari, S.P., Gevaerts, V., Paulusse, J.M.J., Zuilhof, H.: Biofunctional silicon nanoparticles by means of thiol-ene click chemistry. Chem. Asian J. 6, 2776-2786 (2011)

48. Sweryda-Krawiec, B., Cassagneau, T., Fendler, J.H.: Surface modification of silicon nanocrystallites by alcohols. J. Phys. Chem. B. 103, 9524-9529 (1999)

49. Hallmann, S., Fink, M.J.: Mechanochemical synthesis of functionalized silicon nanoparticles with terminal chlorine groups. J. Mater. Res. 26, 1052-1060 (2011)

50. Rosso-Vasic, M., Spruijt, E., Popovic, Z., Overgaag, K., Lagen, B., Grandidier, B., Vanmaekelbergh, D., Dominguez-Gutierrez, D., De Cola, L., Zuilhof, H.: Amine-terminated silicon nanoparticles: synthesis, optical properties and their use in bioimaging. J. Mater. Chem. 19, 5926-5933 (2009)

51. Kang, Z.H., Liu, Y., Tsang, C.H.A., Ma, D.D.D., Fan, X., Wong, N.B., Lee, S.T.: Watersoluble silicon quantum dots with wavelength-tunable photoluminescence. Adv. Mater. 21, 661-664 (2009)

52. He, Y., Su, Y.Y., Yang, X.B., Kang, Z.H., Xu, T.T., Zhang, R.Q., Fan, C., Lee, S.T.: Photo and $\mathrm{pH}$ stable, highly-luminescent silicon nanospheres and their bioconjugates for immunofluorescent cell imaging. J. Am. Chem. Soc. 131, 4434-4438 (2009) 
53. He, Y., Fan, C., Lee, S.-T.: Silicon nanostructures for bioapplications. Nano Today 5, 282-295 (2010)

54. Wang, J., Liu, Y., Peng, F., Chen, C., He, Y., Ma, H., Cao, L., Sun, S.: A general route to effi cient functionalization of silicon quantum dots for high-performance fluorescent probes. Small 8, 2430-2435 (2012)

55. Gongalsky, M.B., Yu, K.A., Osminkina, L.A., Yu, T.V., Jeong, J., Lee, H. Chung, B.H.: Enhanced photoluminescence of porous silicon nanoparticles coated by bioresorbable polymers, Nanoscale Res. Lett. 7, art.446 (2012)

56. Li, Z.F., Ruckenstein, E.: Water-soluble poly (acrylic acid) grafted luminescent silicon nanoparticles and their use as fluorescent biological staining labels. Nano Lett. 4, art. 14631467 (2004)

57. Zhang, X., Neiner, D., Wang, S., Louie, A.Y., Kauzlarich, S.M.: A new solution route to hydrogen-terminated silicon nanoparticles: synthesis, functionalization and water stability. Nanotechnology. 18, art. 095601 (2007)

58. Sudeep, P.K., Page, Z., Emrick, T.: PEGylated silicon nanoparticles: synthesis and characterization. Chem. Commun. 46, 6126-6127 (2008)

59. Wang, K., Wang, Q., Chao, Y.: Simple fabrication of nanostructured silicon and photoluminescence. Appl. Phys. A 109, 437-440 (2012)

60. Ge, J., Liu, W., Zhao, W., Zhang, H., Zhuang, X., Lan, M., Wang, P., Li, H., Ran, G., Lee, S.T.: Preparation of highly stable and water-dispersible silicon quantum dots by using an organic peroxide. Chem. Eur. J. 17, 12872-12876 (2011)

61. Erogbogbo, F., Chang, C.-W., May, J.L., Liu, L., Kumar, R., Law, W.-C., Ding, H., Yong, K.T., Roy, I., Sheshadri, M., Swihart, M.T., Prasad, P.N.: Bioconjugation of luminescent silicon quantum dots to gadolinium ions for bioimaging applications. Nanoscale 4, 5483-5489 (2012)

62. May, J.L., Erogbogbo, F., Yong, K.-T., Ding, H., Law, W.-C., Swihart, M.T., Prasad, P.N.: Enhancing silicon quantum dot uptake by pancreatic cancer cells via pluronic ${ }^{\circledR}$ encapsulation and antibody targeting. J. Solid Tumors 2, 24-37 (2012)

63. Fan, J.Y., Wu, X.L., Chu, P.K.: Low-dimensional SiC nanostructures: fabrication, luminescence, and electrical properties. Prog. Mat. Sci. 51, 983-1031 (2006)

64. Matsumoto, T., Takahashi, J., Tamaki, T., Futagi, T,. Mimura, H., Kanemitsu, Y.A.: Bluegreen luminescence from porous silicon carbide. Appl. Phys. Lett. 64, art. 226 (1994)

65. Petrova-Koch, V., Sreseli, O., Polisski, G., Kovalev, D., Muschik, T., Koch, F.: Luminescence enhancement by electrochemical etching of $\mathrm{SiC}(6 \mathrm{H})$. Thin Solid Films 255 , $107-110$ (1995)

66. Rossi, A.M., Murphy, Th.E., Reipa, V.: Ultraviolet photoluminescence from $6 \mathrm{H}$ silicon carbide nanoparticles. Appl. Phys. Lett. 92, art.253112 (2008)

67. Botsoa, J., Bluet, J.-M., Lysenko, V., Marty, O., Barbier, D., Guillot, G.: Photoluminescence of $6 \mathrm{H}-\mathrm{SiC}$ nanostructures fabricated by electrochemical etching. J. Appl. Phys. 102, art. 083526 (2007)

68. Wu, X.L., Fan, J.Y., Qiu, T., Yang, X., Siu, G.G., Chu, P.K.: Experimental evidence for the quantum confinement effect in 3C-SiC Nanocrystallites. Phys. Rev. Lett. 94, art. 026102 (2005)

69. Fan, J.Y., Wu, X.L., Li, H.X., Liu, H.W., Siu, G.G., Chu, P.K.: Luminescence from colloidal 3C-SiC nanocrystals in different solvents. Appl. Phys. Lett. 88, art. 041909 (2006)

70. Zakharko, Y., Botsoa, J., Alekseev, S., Lysenko, V., Bluet, J.-M., Marty, O., Skryshevsky, V.A., Guillot, G.: Influence of the interfacial chemical environment on the luminescence of 3C- SiC nanoparticles. J. Appl. Phys. 107, art. 013503 (2010)

71. Serdiuk, T., Alekseev, S.A., Lysenko, V., Skryshevsky, V.A., Géloën, A.: Charge-driven selective localization of fluorescent nanoparticles in live cells. Nanotechnology 23, art.315101 (2012)

72. Alekseev, S., Botsoa, J., Zaitsev, V.N., Barbier, D.: Fourier transform infrared spectroscopy and temperature programmed desorption mass spectrometry study of surface chemistry of porous $6 \mathrm{H}-\mathrm{SiC}$. Chem. Mater. 19, 2189-2194 (2007) 
73. Shin, W., Seo, W., Takai, O., Koumoto, K.: Surface chemistry of porous silicon carbide. J. Electron. Mater. 27, 304-307 (1998)

74. Beke, D., Szekre'nyes, Z., Balogh, I., Veres, M., Fazakas, E., Varga, L.K., Kamara's, K., Cziga'ny, Z., Gali, A.: Characterization of luminescent silicon carbide nanocrystals prepared by reactive bonding and subsequent wet chemical etching, Appl. Phys. Lett. 99, art. 213108 (2011)

75. Li, Y., Chen, C., Li, J.-T., Yang, Y., Lin, Z.-M.: Surface charges and optical characteristic of colloidal cubic SiC nanocrystals. Nanoscale Res. Lett. 6, art. 454 (2011)

76. Zhang, N., Dai, D., Zhang, W., Fan, J.: Photoluminescence and light reabsorption in SiC quantum dots embedded in binary-polyelectrolyte solid matrix. J. Appl. Phys. 112, art. 094315 (2012)

77. Che, J., Wang, X., Xiao, Y., Wu, X., Zhou, L., Yuan, W.: Effect of inorganic-organic composite coating on the dispersion of silicon carbide nanoparticles in non-aqueous medium. Nanotechnology 18, art.135706 (2007)

78. Iijima, M., Kamiya, H.: Surface modification of silicon carbide nanoparticles by azo radical initiators. J. Phys. Chem. C 112, 11786-11790 (2008)

79. Pud, A.A., Noskov, Y.V., Kassiba, A., Fatyeyeva, K.Y., Ogurtsov, N.A., Makowska-Janusik, M., Bednarski, W., Tabellout, M., Shapoval, G.S.: New aspects of the low-concentrated aniline Polymerization in the solution and in SiC nanocrystals dispersion. J. Phys. Chem. B. 111, 2174-2180 (2007)

80. Serdiuk, T., Lysenko, V., Skryshevsky, V.A., Géloën, A.: Vapor phase mediated cellular uptake of sub $5 \mathrm{~nm}$ nanoparticles. Nanoscale Res. Lett. 7: art. 212 (2012)

81. Serdiuk, T., Lysenko, V., Mognetti, B., Skryshevsky, V., Géloën, A.: Impact of cell division on intracellular uptake and nuclear targeting with fluorescent SiC-based nanoparticles. J. Biophotonics 6, 291-297 (2013)

82. Tagliazucchi, M., Peleg, O., Kroger, M., Rabin, Y., Szleifer, I.: Effect of charge, hydrophobicity, and sequence of nucleoporins on the translocation of model particles through the nuclear pore complex. PNAS 110, 3363-3368 (2013)

83. Weisburg, J.H., Weissman, D.B., Sedaghat, T., Babich, H.: In vitro cytotoxicity of epigallocat echin gallate and tea extracts to cancerous and normal cells from the human oral cavity, Basic Clin. Pharmacol. Toxicol. 95, 191-200 (2004)

84. Zakharko, Yu., Serdiuk, T., Nychyporuk, T., Geloen, A., Lemiti, M., Lysenko, V.: Plasmonenhanced photoluminescence of $\mathrm{SiC}$ quantum dots for cell imaging applications. Plasmonics 7, 725-732 (2012) 